\title{
Quest for new materials: Inorganic chemistry plays a crucial role ${ }^{\dagger}$
}

\author{
J GOPALAKRISHNAN* and ROHINI MANI \\ Solid State and Structural Chemistry Unit, Indian Institute of Science, Bangalore 560012 \\ e-mail: gopal@sscu.iisc.ernet.in
}

MS received 24 February 2009; revised 17 April 2009

\begin{abstract}
There is an endless quest for new materials to meet the demands of advancing technology. Thus, we need new magnetic and metallic/semiconducting materials for spintronics, new low-loss dielectrics for telecommunication, new multi-ferroic materials that combine both ferroelectricity and ferromagnetism for memory devices, new piezoelectrics that do not contain lead, new lithium containing solids for application as cathode/anode/electrolyte in lithium batteries, hydrogen storage materials for mobile/transport applications and catalyst materials that can convert, for example, methane to higher hydrocarbons, and the list is endless! Fortunately for us, chemistry - inorganic chemistry in particular - plays a crucial role in this quest. Most of the functional materials mentioned above are inorganic non-molecular solids, while much of the conventional inorganic chemistry deals with isolated molecules or molecular solids. Even so, the basic concepts that we learn in inorganic chemistry, for example, acidity/basicity, oxidation/reduction (potentials), crystal field theory, low spin-high spin/inner sphere-outer sphere complexes, role of $d$-electrons in transition metal chemistry, electron-transfer reactions, coordination geometries around metal atoms, Jahn-Teller distortion, metal-metal bonds, cation-anion (metal-nonmetal) redox competition in the stabilization of oxidation states - all find crucial application in the design and synthesis of inorganic solids possessing technologically important properties. An attempt has been made here to illustrate the role of inorganic chemistry in this endeavour, drawing examples from the literature as well as from the research work of my group.
\end{abstract}

Keywords. Materials for technology; role of inorganic chemistry; acidity/basicity; oxidation/reduction; crystal field theory; Jahn-Teller distortions; mixed valence; metal-metal bonding.

\section{Introduction}

It is indeed a truism to say that there is an insatiable quest for new materials to meet the demands of advancing technology. Some of the materials need for today's technology is listed in table 1. The table is self-explanatory, but a few comments are in order. While lightweight and superhard materials such as $\mathrm{Si} / \mathrm{B} / \mathrm{C} / \mathrm{N}$ ceramics are required for aerospace industry, ${ }^{1}$ solid materials that do not expand on heating ${ }^{2}$ have several applications including in spacecraft, optical fibres and even the ordinary oven cookware (resistance to thermal shock). In the context of energy crunch (due to declining fossil fuel reserves), environmental pollution and global warming, there are several materials requirements to meet the challenges: for example, more efficient photocatalytic materials (than the currently used $\mathrm{TiO}_{2}$ ) for the effective utili-

\footnotetext{
${ }^{\dagger}$ This article is based on the invited lecture delivered by Professor J Gopalakrishnan in the MTIC-XII Symposium held at Indian Institute of Technology (IIT) Madras in December 2007 *For correspondence
}

zation of solar energy, ${ }^{3,4}$ better materials for anode, cathode and electrolyte for fuel cells ${ }^{5}$ and lithium batteries, ${ }^{6}$ thermoelectric materials that can convert heat into electricity, ${ }^{7}$ materials that can produce large quantities of hydrogen cheaply and store them reversibly ${ }^{8}$ are some of the prime targets of current research efforts under the theme ${ }^{9}$ of 'materials for clean energy technologies'. To quote from a special issue of Inorganic Chemistry ${ }^{10}$ devoted to this area of research: "clearly, the challenge for 21 st century is energy, and the answers to that challenge lie mainly in chemistry, with the discipline of inorganic chemistry playing a central role. What chemists do to address this challenge will have impact reaching far beyond our laboratories and institutions'. In addition, advancing electronics industry requires newer materials for spintronics ${ }^{11}$ (spin based electronics where not only the charge but also the spin of the electron is involved), multi-ferroics ${ }^{12}$ (where two or more ferroic properties such as ferromagnetism and ferroelectricity are coupled in the same material), and optoelectronic device applications (where trans- 
Table 1. New materials for advancing technology.

\begin{tabular}{|c|c|}
\hline Materials/property required & Prototype/recent examples and remarks \\
\hline Superhard materials & Diamond, c-BN, c- $\mathrm{BC}_{2} \mathrm{~N}, \mathrm{Si} / \mathrm{B} / \mathrm{N} / \mathrm{C}$ ceramics \\
\hline Zero thermal expansion materials & $\mathrm{ZrW}_{2} \mathrm{O}_{8}, \mathrm{YGaGe}^{\prime}$ \\
\hline Photocatalyst materials & $\mathrm{TiO}_{2}, \mathrm{TaON}$ \\
\hline Transparent conductors & $\mathrm{ZnO}, \mathrm{SnO}_{2}, \mathrm{In} / \mathrm{SnO}_{2}(\mathrm{ITO})$, Copper delafossites, $\mathrm{CuMO}_{2}(\mathrm{M}=\mathrm{Al}, \mathrm{Ga}, \mathrm{Fe})$ \\
\hline $\begin{array}{l}\text { Phonon - glass electron - crystal } \\
\text { (PGEC) materials }\end{array}$ & Skutterudites, $\mathrm{CoX}_{3}(\mathrm{X}=\mathrm{P}, \mathrm{As}, \mathrm{Sb})$, Zintl phases, $\mathrm{CaZn}_{2} \mathrm{Sb}_{2}$ \\
\hline \multicolumn{2}{|l|}{ Materials for clean energy } \\
\hline (i) Fuel cells & $\begin{array}{l}\mathrm{Sr}_{2}(\mathrm{Mg}, \mathrm{Mn}) \mathrm{MoO}_{6} \text { (anode), Apatites, } \mathrm{M}_{10}\left(\mathrm{XO}_{4}\right)_{6} \mathrm{O}_{2+y} \text { (electrolyte), } \\
\mathrm{SrCo}_{0.8} \mathrm{Fe}_{0.2} \mathrm{O}_{3-y} \text { (cathode), } \mathrm{GdBaCo}_{2} \mathrm{O}_{5+x} \text { (cathode) }\end{array}$ \\
\hline (ii) Lithium batteries & $\mathrm{Li}(\mathrm{Ni}, \mathrm{Mn}) \mathrm{O}_{2}, \mathrm{LiFePO}_{4}$ (cathode), $\mathrm{MnP}_{4}, \mathrm{ZnP}_{2}$ (anode), $\mathrm{Si}-\mathrm{C}-\mathrm{Al}$ composite \\
\hline (iii) Hydrogen storage & Metal-organic-frameworks (MOFs) \\
\hline Spintronic materials & $\begin{array}{l}\text { Halfmetallic ferromagnets (Fe-Cr multilayers, } \mathrm{La}_{1-x} \mathrm{Ca}_{x} \mathrm{MnO}_{3} \text {, } \\
\left.\mathrm{Sr}_{2} \mathrm{FeMoO}_{6}\right) \text {, Ferromagnetic semiconductors }\left(\operatorname{In}_{1-x} \mathrm{Mn}_{x} \mathrm{As}\right)\end{array}$ \\
\hline Multi-ferroic materials & $\begin{array}{l}\mathrm{BiMnO}_{3} \text { (ferromagnetic } T_{C} \approx 100 \mathrm{~K} \text {, ferroelectric } T_{C} \sim 760 \mathrm{~K} \text { ) } \mathrm{CdCr}_{2} \mathrm{~S}_{4} \\
\quad \text { (ferromagnetic ferroelectric } T_{C} \sim 90 \mathrm{~K} \text { ) }\end{array}$ \\
\hline Lead-free piezoelectrics & $\mathrm{PbZr}_{0.52} \mathrm{Ti}_{0.48} \mathrm{O}_{3}, \mathrm{~K}_{0.5} \mathrm{Na}_{0.5} \mathrm{NbO}_{3}-\mathrm{LiNbO}_{3}$ \\
\hline High temperature superconductors & $\begin{array}{l}\mathrm{Tl}_{0.5} \mathrm{~Pb}_{0.5} \mathrm{Sr}_{2} \mathrm{Ca}_{2} \mathrm{Cu}_{3} \mathrm{O}_{9}\left(T_{C} \sim 120 \mathrm{~K}\right), \mathrm{HgBa}_{2} \mathrm{Ca}_{2} \mathrm{Cu}_{3} \mathrm{O}_{8}\left(T_{C} \sim 164 \mathrm{~K}\right. \\
\quad \text { under pressure })\end{array}$ \\
\hline
\end{tabular}

parent conductors, ${ }^{13}$ especially of the $p$-type, are required for LEDs, flat panel displays and solar cells), among others. Piezoelectrics such as $\mathrm{PbZr}_{0.52}$ $\mathrm{Ti}_{0.48} \mathrm{O}_{3}$ perovskites, which are widely used as sensors and actuators contain a large proportion of lead that is environmentally harmful; here the crucial challenge for materials chemists is to produce new materials without lead ${ }^{14}$ that are as good or even better than the currently used lead-containing materials. Last but not the least, the grand materials challenge is in the realm of high-temperature superconductors, where the dream is to synthesize a room-temperature superconductor! ${ }^{15}$

One might wonder what is the relevance of chemistry - that too inorganic chemistry - for all the foregoing problems in materials science. The quest for new materials can only be met by synthesizing them and synthesis is very much in the domain of chemistry. In a recent article in Nature ${ }^{16}$ probing into what are the challenges for chemistry yet to be solved, synthesis - the art of creating new substances - be they isolated molecules or extended solids, is identified as the major forte of chemistry. The case for chemistry for the synthesis of new materials is loud and clear: "if room-temperature superconductors or synthetic bacteria are ever created, it will not be physicists and biologists who will make them!'. A special word about the role of inorganic chemistry in the quest for new materials: while the discipline of chemistry as a whole plays a crucial role in this quest - physical chemistry for instance helps resolve issues like stability vs metastability/thermodynamics vs kinetic control of synthesis, inorganic chemistry, by its very nature of being the chemistry of all the elements and their compounds, is of special significance in the quest for new materials, for the simple reason that almost all the new materials that are sought (see table 1) are extended inorganic solids, mostly oxide materials comprising transition and non-transition elements. Accordingly, a sound knowledge of inorganic chemistry - both transition and non-transition elements chemistry - is essential for the practice of materials chemistry. Materials chemists constantly employ the fundamental principles of inorganic chemistry, ${ }^{17}$ either implicitly or explicitly, in the pursuit of their profession. In this article, we shall endeavour to bring out this point with several examples drawn from the literature as well as from our work.

\section{Role of inorganic chemistry in the quest for new materials}

Inorganic chemistry ${ }^{17}$ is mainly concerned with isolated molecules or molecular solids where one can discern the presence of finite molecular/ionic entities, whereas materials science deals with (mostly inorganic) solids that are invariably non-molecular. ${ }^{18}$ This difference poses a conceptual problem for a conventional (inorganic) chemist wanting to do materials science, but this is indeed an advantage because most of the basic concepts that one learns in inor- 
ganic chemistry find useful and rewarding application in the practice of materials science. Some of the basic concepts that one learns in inorganic chemistry are: acidity/basicity, oxidation/reduction (potentials), role of $d$-electrons in transition metal chemistry: crystal field theory, coordination geometries, low spin-high spin/inner sphere-outer sphere complexes, Jahn-Teller distortions, electron transfer reactions, metal-metal bonds, stabilization of oxidation states and cation-anion (metal - nonmetal) redox competition. We shall now try to illustrate how some of these ideas find application in the practice of materials chemistry.

\subsection{Acidity/basicity}

As inorganic chemists, we are familiar with Bronsted and Lewis acidity: Bronsted acidity involves protons (transfer) and Lewis acidity concerns electron pairs (donor/acceptor). Also we know that acidity in general increases with oxidation state and that, for a given oxidation state, it increases from left to right in a Period and from bottom to top in a Group, for elements in the Periodic Table. Evolution of acidity of metal ions in aqueous media could be understood in terms of polarization/dissociation of the water molecule attached to the metal ions:

$$
\mathrm{M}^{\mathrm{n}+}-\left(\mathrm{OH}_{2}\right) \leftrightarrow \mathrm{M}^{\mathrm{n}+}-\mathrm{OH}+\mathrm{H}^{+} \leftrightarrow \mathrm{M}^{\mathrm{n}+}=\mathrm{O}+\mathrm{H}^{+}
$$

aqua acid hydroxoacid oxoacid

$\mathrm{Fe}^{3+}, \mathrm{Al}^{3+} / \mathrm{Si}^{4+}$ and $\mathrm{Cr}^{6+}$ in aqueous solutions are typical examples for aqua acids, hydroxoacid and oxoacid behaviour, respectively. ${ }^{17}$ The progressive increase of acidity with oxidation states of metal ions in aqueous media is also reflected in acid/base character of metal oxides in the solid state. ${ }^{17 b} \mathrm{Ac}$ cordingly, oxides of transition metals in their highest oxidation state ( $d^{0}$ electronic configuration) are highly acidic oxides that are readily hydrated to give solid Bronsted acids. Thus,

$$
\begin{aligned}
& \mathrm{TiO}_{2}+x \mathrm{H}_{2} \mathrm{O} \rightarrow \mathrm{TiO}_{2} \cdot x \mathrm{H}_{2} \mathrm{O} \equiv \mathrm{H}_{2} \mathrm{Ti}_{3} \mathrm{O}_{7}, \mathrm{H}_{2} \mathrm{Ti}_{4} \mathrm{O}_{9} \\
& \mathrm{MoO}_{3}+\mathrm{H}_{2} \mathrm{O} \rightarrow \mathrm{MoO}_{3} \cdot \mathrm{H}_{2} \mathrm{O} \equiv \mathrm{H}_{2} \mathrm{MoO}_{4} .
\end{aligned}
$$

The hydrated oxides are unique solids possessing well-defined structures different from the parent oxides (figure 1). The layered structures of the hydrated oxides, where the acidic protons reside within the galleries, make them ideal host materials to carry out intercalation and other appropriate interlayer chemistry. ${ }^{18}$
$\mathrm{MoO}_{3} \cdot \mathrm{H}_{2} \mathrm{O}$ and $\mathrm{WO}_{3} \cdot \mathrm{H}_{2} \mathrm{O}$ are typical examples of hydrated oxides whose structures are different from the corresponding anhydrous oxides (figure 1); the water molecule is directly coordinated to the metal and the protons are polarized to make them acidic. The Bronsted acidity of both the oxide hydrates are well-established by their intercalation reactivity towards a variety of organic bases ${ }^{19}$ including ammonia, $n$-alkylamines, and even a weak base such as aniline. Formation of a dihydrate $\mathrm{MO}_{3} \cdot 2 \mathrm{H}_{2} \mathrm{O}$ could also be regarded as a manifestation of Bronsted acidity of the monohydrates $\mathrm{MO}_{3} \cdot \mathrm{H}_{2} \mathrm{O}$ $(\mathrm{M}=\mathrm{Mo}, \mathrm{W})$. The second water molecule in the dihydrates is held in between the layers through a unique set of hydrogen bonds, that suggests a tendency towards protonation of the second water molecule:

$$
\begin{array}{r}
\mathrm{MoO}_{3} \cdot \mathrm{H}_{2} \mathrm{O}+\mathrm{H}_{2} \mathrm{O} \rightarrow\left[\mathrm{MoO}_{3} \mathrm{OH}^{-}\right] \mathrm{H}_{3} \mathrm{O}^{+} \equiv \\
\mathrm{MoO}_{3} \cdot 2 \mathrm{H}_{2} \mathrm{O} .
\end{array}
$$

The dihydrates in turn are also solid acids intercalating a variety of $n$-alkylamines forming low-dimensional nanostructures. ${ }^{20}$

Recognition of the foregoing general ideas relating to acidity/basicity of metal oxides has lead to the synthesis of several new metal oxide hydrates that exhibit Bronsted acidity. Most of them containing $d^{0}$ metal atoms adopt layered structures, facilitating acid-base intercalation and related interlayer chemistry. The new materials ${ }^{21-28}$ include $\mathrm{W}_{1-x} \mathrm{Mo}_{x} \mathrm{O}_{3} \cdot n \mathrm{H}_{2} \mathrm{O}$, $\mathrm{H}_{x} \mathrm{~V}_{x} \mathrm{~W}_{1-x} \mathrm{O}_{3} \cdot n \mathrm{H}_{2} \mathrm{O}, \quad \mathrm{V}_{2} \mathrm{O}_{5} \cdot n \mathrm{H}_{2} \mathrm{O}$ gel, $\mathrm{HNb}_{3} \mathrm{O}_{8}$, $\mathrm{HTiNbO}_{5}, \mathrm{HNbMO}_{6}$ and $\mathrm{HTaMO}_{6}(\mathrm{M}=\mathrm{Mo}, \mathrm{W})$, $\mathrm{HLaNb}_{2} \mathrm{O}_{7}, \mathrm{HCa}_{2} \mathrm{Nb}_{3} \mathrm{O}_{10}, \mathrm{H}_{2} \mathrm{La}_{2} \mathrm{Ti}_{3} \mathrm{O}_{10}, \mathrm{HLaTiO}_{4}$ and so on. Many of the materials were synthesized for the first time in our group. Bronsted acidity is generally revealed by intercalation experiments with $n$-alkylamines and other bases. In favourable instances, base intercalation could be used to grade the relative acidity of the host materials. ${ }^{26}$ Representative examples of this kind of layered materials are $\mathrm{HNbMO}_{6}$ and $\mathrm{Ta}$ analogs (figure 2). These oxides are synthesized from their corresponding trirutile $\mathrm{Li}$ analogs $\mathrm{LiNbMO}_{6}$ and $\mathrm{LiTaMO}_{6}$ by $\mathrm{Li}^{+} / \mathrm{H}^{+}$exchange in dilute $\mathrm{HNO}_{3}$. The monohydrates $\mathrm{HNbMO}_{6} \cdot \mathrm{H}_{2} \mathrm{O}$ and $\mathrm{HTaMO}_{6} \cdot \mathrm{H}_{2} \mathrm{O}$ are strong Bronsted acids intercalating $\mathrm{NH}_{3}$ and a wide variety of organic bases. Among these, $\mathrm{HNbMoO}_{6} \cdot \mathrm{H}_{2} \mathrm{O}$ turned out to be the strongest Bronsted acid intercalating weak bases such as pyrrole $\left(p K_{a}=0.4\right)$ and nitroanilines $\left(p K_{a}=\right.$ 1-2.5). Interestingly, the host (and its intercalates) retain the non-centrosymmetric structure of the parent 


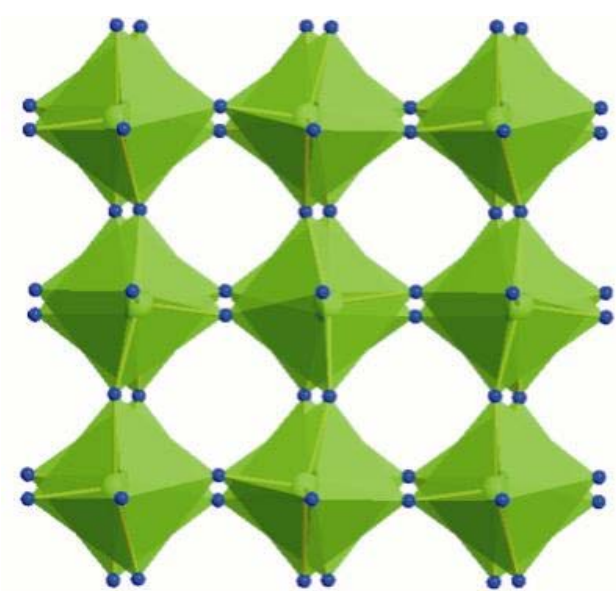

(a)

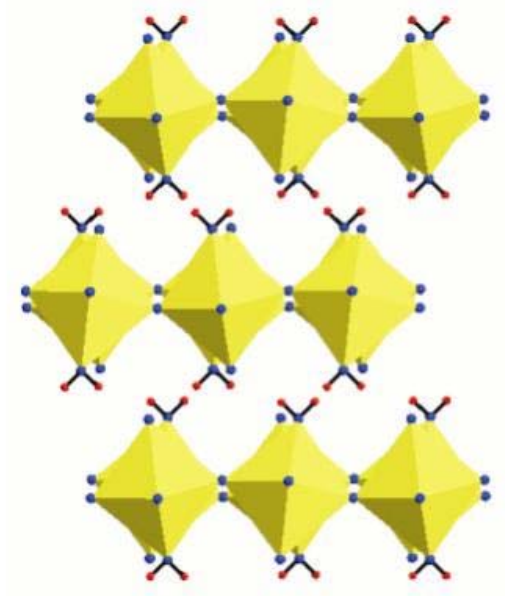

(c)

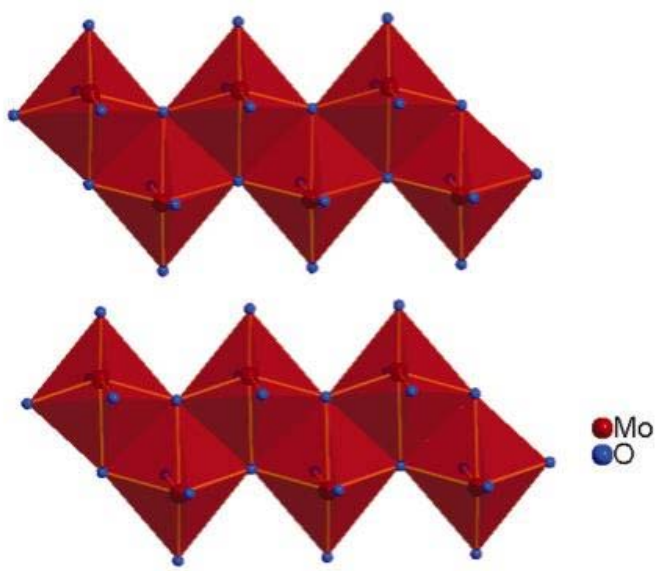

(b)

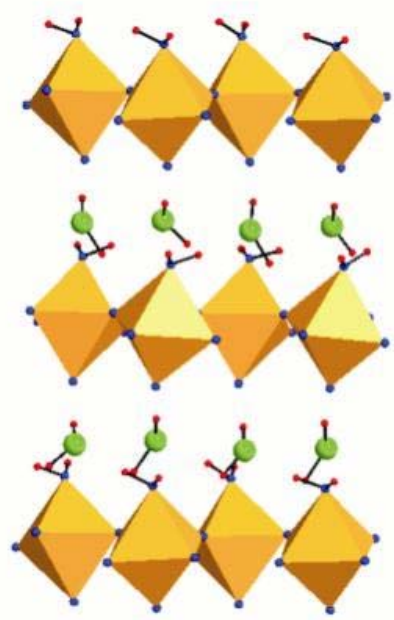

(d)

Figure 1. Structures of (a) $\mathrm{WO}_{3}$, (b) $\mathrm{MoO}_{3}$, (c) $\mathrm{MO}_{3} \cdot \mathrm{H}_{2} \mathrm{O}$ and (d) $\mathrm{MO}_{3} \cdot 2 \mathrm{H}_{2} \mathrm{O}(\mathrm{M}=\mathrm{Mo}$, W). Structures (c) and (d) are adopted by $\mathrm{H}_{x} \mathrm{~V}_{x} \mathrm{~W}_{1-x} \mathrm{O}_{3} \cdot n \mathrm{H}_{2} \mathrm{O}$ also.

lithium oxides. Thus, several $n$-alkylamine intercalates of $\mathrm{HNbWO}_{6}$ and $\mathrm{HNbMoO}_{6}$ exhibit second harmonic generation (SHG) of $1064 \mathrm{~nm}$ radiation even when the basal spacings are expanded by large distances. ${ }^{29} \mathrm{HNbMoO}_{6}$ and its analogs are versatile multiproperty materials where aniline has been intercalated and polymerized to give (PANI) ${ }_{x} \mathrm{NbMO}_{6}$ $(\mathrm{M}=\mathrm{Mo}, \mathrm{W})$. Also these materials have been exfoliated into nanosheets and restacked with other guest species to give new functional materials.

Ion exchange and intercalation experiments carried out with layered perovskites have provided a new understanding of the Bronsted acidity of this class of materials. ${ }^{27}$ Thus $\mathrm{HCa}_{2} \mathrm{Nb}_{3} \mathrm{O}_{10}$ (figure 2) and $\mathrm{HLaNb}_{2} \mathrm{O}_{7}$ are strong Bronsted acids, intercalating a wide variety of organic bases including aniline $\left(p K_{a}=4.63\right)$ and pyridine $\left(p K_{a}=5 \cdot 3\right) . \mathrm{H}_{2} \mathrm{La}_{2} \mathrm{Ti}_{3} \mathrm{O}_{10}$ (figure 3 ) and its isostructural derivatives $\mathrm{H}_{2-x} \mathrm{La}_{2}$
$\mathrm{Ti}_{3-x} \mathrm{Nb}_{x} \mathrm{O}_{10}$ do not exhibit an obvious Bronsted acidity, as revealed by their inability to intercalate even strong bases such as piperidine $\left(p K_{a}=11.2\right)$ and guanidine $\left(p K_{a}=12.5\right)$. This lack of intercalation reactivity of protons of $\mathrm{H}_{2} \mathrm{La}_{2} \mathrm{Ti}_{3} \mathrm{O}_{10}$ and its ana$\operatorname{logs}$ seems to be related to a special interlayer structure arising from displacement of perovskite slabs and does not reflect the intrinsic acidity of the protons. In another series of layered perovskites $\mathrm{HCa}_{2-x} \mathrm{La}_{x} \mathrm{Nb}_{3-x} \mathrm{Ti}_{x} \mathrm{O}_{10}(0 \leq x \leq 2)$ which are isostructural with $\mathrm{HCa}_{2} \mathrm{Nb}_{3} \mathrm{O}_{10}$, ${ }^{27}$ we could tune the acidity of the protons by the replacement of $\mathrm{Nb}$ with $\mathrm{Ti}$. $\mathrm{HLa}_{2} \mathrm{NbTi}_{2} \mathrm{O}_{10}$ is a weak Bronsted acid intercalating piperidine with great difficulty. It does not intercalate other bases with $p K_{a}<11$, while the protons of $\mathrm{HCa}_{2} \mathrm{Nb}_{3} \mathrm{O}_{10}$ are strongly acidic. Since both the compounds are isostructural, this difference in intercalation reactivity truly reflects the intrinsic acidity 


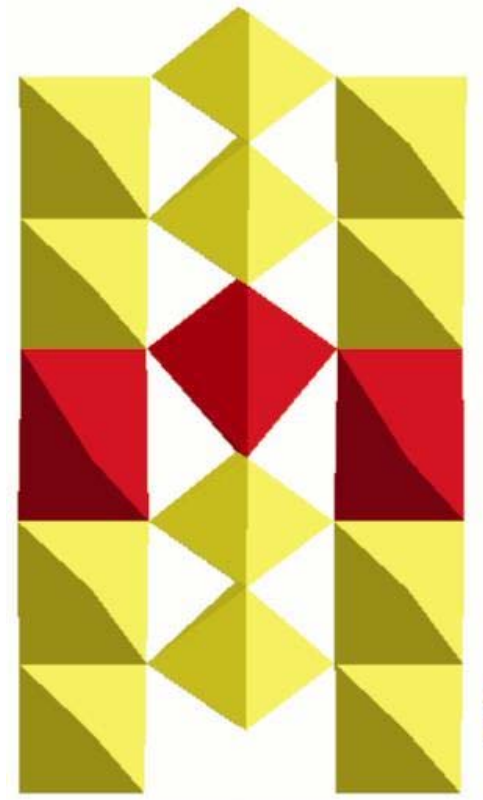

(a)

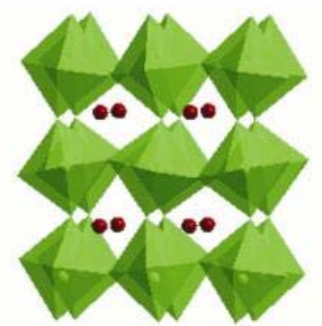

. .

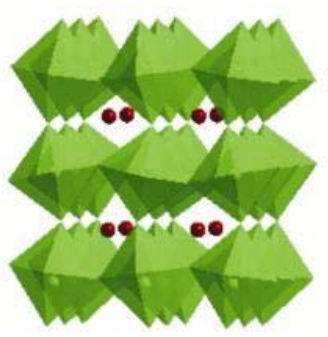

(c)
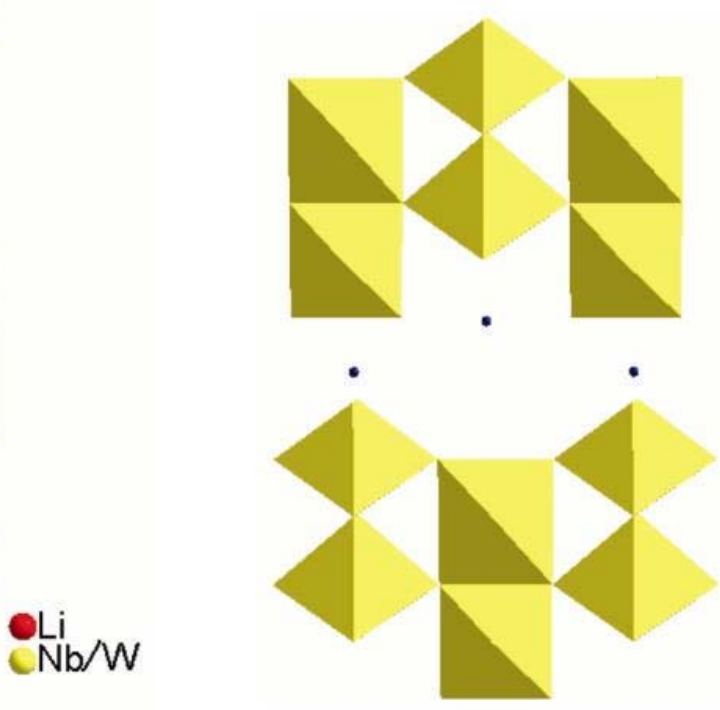

(b)
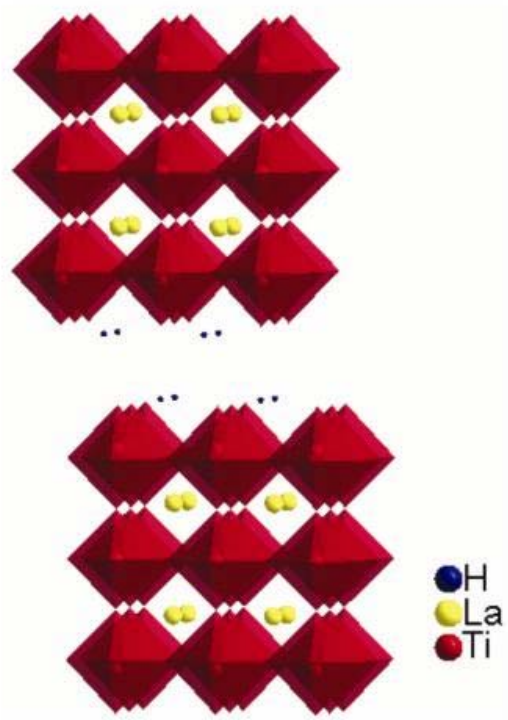

(d)

Figure 2. Structures of (a) $\mathrm{LiNbWO}_{6}$, (b) $\mathrm{HNbWO}_{6}$, (c) $\mathrm{HCa}_{2} \mathrm{Nb}_{3} \mathrm{O}_{10}$ and (d) $\mathrm{H}_{2} \mathrm{La}_{2} \mathrm{Ti}_{3} \mathrm{O}_{10}$.

difference of the protons attached to $\mathrm{NbO}_{6}$ and $\mathrm{TiO}_{6}$ octahedra.

\subsection{Oxidation/reduction}

A knowledge of the redox chemistry is crucial to the practice of solid state chemistry involving transition metals. Oxidation-reduction processes in solution chemistry and redox potentials of metal ions obtained for aqueous media could be used as a rough guide for understanding the reactivities of metal atoms in the solid state. Thus, the non-existence of $\mathrm{CuI}_{2}$ and $\mathrm{FeI}_{3}$ as stable compounds could be understood in terms of the redox potentials, $\mathrm{I}_{2} / \mathrm{I}^{-}(0.54 \mathrm{~V})$, $\mathrm{Cu}^{2+} / \mathrm{Cu}^{+}(0 \cdot 15 \mathrm{~V})$ and $\mathrm{Fe}^{3+} / \mathrm{Fe}^{2+}(0 \cdot 77 \mathrm{~V})$. Similarly, while $\mathrm{Fe}_{2} \mathrm{O}_{3}$ and $\mathrm{Fe}_{3} \mathrm{O}_{4}$ are well known oxides, the corresponding thio analogs are not known; $\mathrm{Fe}_{2} \mathrm{~S}_{3}$ when prepared turns out to be a mixture of $\mathrm{FeS}$ and $\mathrm{FeS}_{2}$, and $\mathrm{FeS}_{2}$ is not $\left(\mathrm{Fe}^{4+}\right)\left(\mathrm{S}^{2-}\right)_{2}$ but $\left(\mathrm{Fe}^{2+}\right)\left(\mathrm{S}_{2}\right)^{2-}$ indicating that in presence of sulphur and other chalcogenides, oxidation state higher than $2^{+}$cannot be stabilized for iron. The same is true with several 


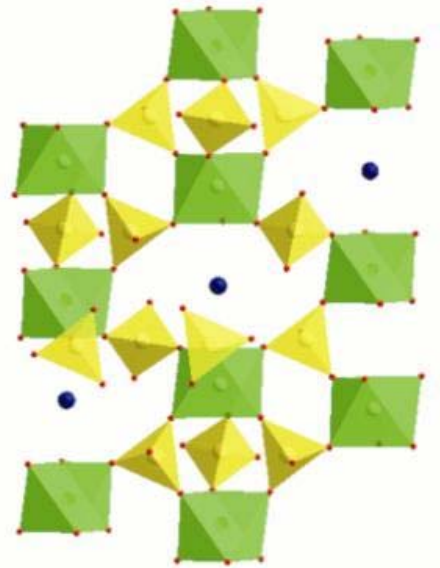

(a)

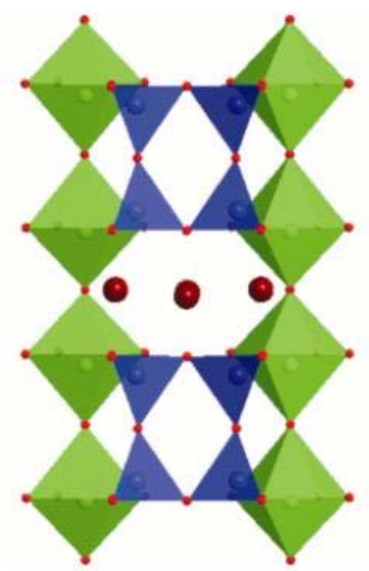

(c)

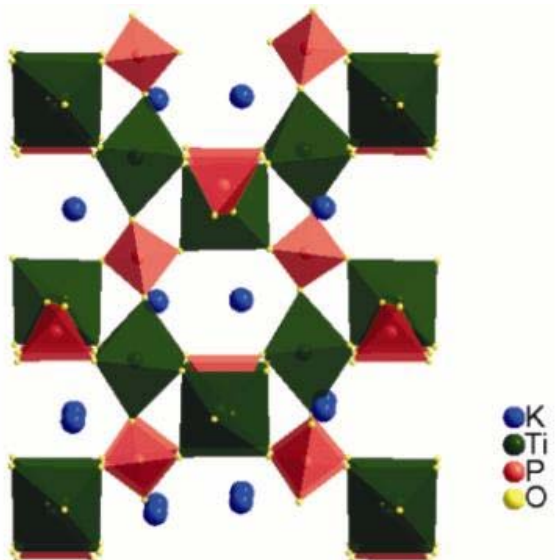

(b)

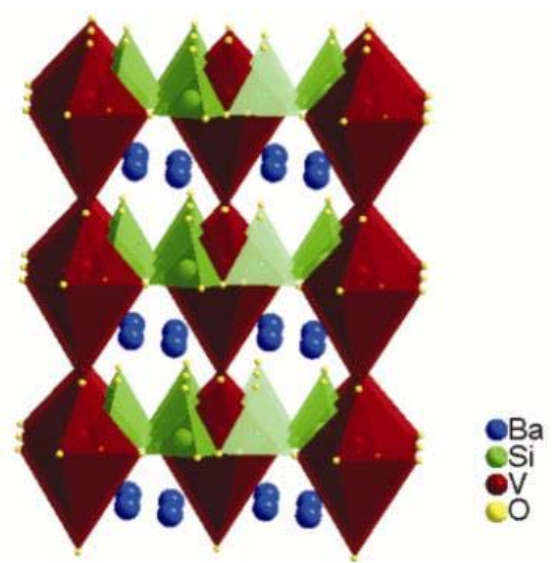

(d)

Figure 3. Frameworks of (a) NASICON, (b) $\mathrm{KTiOPO}_{4}(\mathrm{KTP})$, (c) $\mathrm{K}_{2}(\mathrm{NbO})_{2} \mathrm{Si}_{4} \mathrm{O}_{12}$ and (d) $\mathrm{Ba}_{2} \mathrm{VOSi}_{2} \mathrm{O}_{7}$ (fresnoite).

other transition metals lying to the right side of iron in the Periodic Table. An understanding of the chemistry of transition metals arising from anioncation redox competition in the solid state has been provided by the pioneering works of John Goodenough $^{30}$ and Jean Rouxel. ${ }^{31}$ The idea is simple: bringing highly charged cations and chalcogenides together in a compound results in the oxidation of the anions creating holes in the anion $s-p$ band rather than oxidation of metal atoms. The holes may get eliminated by formation of chalcogen-chalcogen bonds forming $[X-X]^{2-}$.

We have effectively made use of redox chemistry to develop new synthetic routes for the synthesis of solids. We could for instance synthesize a wide variety of oxide bronzes ${ }^{32}$ of tungsten, molybdenum and vanadium, recognizing that the redox potential of $\mathrm{I}^{-} / \mathrm{I}$ is favourable to reduce $\mathrm{W}^{6+}, \mathrm{Mo}^{6+}$ and $\mathrm{V}^{5+}$ to lower oxidation states. We have also extended the strategy to synthesize $\mathrm{CrO}_{2}-\mathrm{a}$ metastable ferromagnetic metallic oxide ${ }^{33}$ This oxide is traditionally synthesized under high pressure-high temperature conditions. We could prepare this material under ambient pressure by the redox reaction

$$
\mathrm{CrO}_{3}+2 \mathrm{NH}_{4} \mathrm{I} \rightarrow \mathrm{CrO}_{2}+2 \mathrm{NH}_{3}+\mathrm{I}_{2}+\mathrm{H}_{2} \mathrm{O} \text {. }
$$

The reaction occurs quantitatively between 120 and $150^{\circ} \mathrm{C}$. We have also used redox deintercalation reactions to prepare $\mathrm{Li}_{1-x} \mathrm{CoO}_{2}$ and $\mathrm{Li}_{2-x} \mathrm{MoO}_{3}$ using $\mathrm{I}_{2}$ in non-aqueous media. More interestingly, we could deintercalate sodium from the NASICON phosphate $\mathrm{Na}_{3} \mathrm{~V}_{2}\left(\mathrm{PO}_{4}\right)_{3}$ employing $\mathrm{Cl}_{2}$ as the oxidizing agent. ${ }^{34}$ $\mathrm{V}_{2}\left(\mathrm{PO}_{4}\right)_{3}$, the product of complete deintercalation, is a new metastable phosphate that retains the NASICON framework (figure 3). We have employed this strategy to prepare new nonlinear optical materials of the $\mathrm{KTiOPO}_{4}$ (KTP) type. ${ }^{35} \mathrm{KTP}$ is a framework phosphate containing one-dimensional channels parallel 


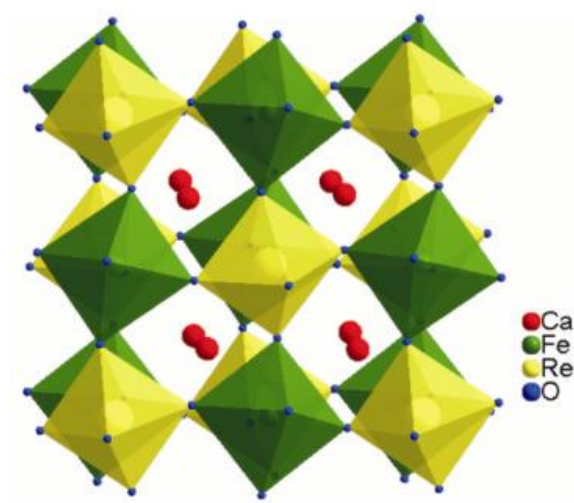

(a)

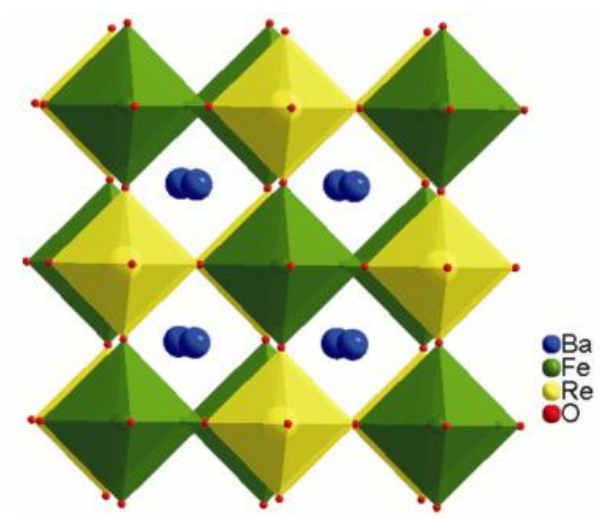

(b)

Figure 4. Crystal structures of (a) $\mathrm{Ca}_{2} \mathrm{FeReO}_{6}$ and (b) $\mathrm{Ba}_{2} \mathrm{FeReO}_{6}$ perovskites.

to [001] where the potassium ions reside (figure 3). The structure allows mobility of $\mathrm{K}^{+}$through the channels resulting in ion exchange and ionic conductivity. Accordingly, we envisaged that it would be possible to oxidatively deintercalate $\mathrm{K}^{+}$from this structure by incorporating appropriate transition metal atoms in the framework. To realize this possibility, we prepared new KTP analogs, $\mathrm{KM}_{0.5}$ $\mathrm{M}_{0.5}^{\prime} \mathrm{OPO}_{4} \quad\left(\mathrm{M}=\mathrm{Nb}^{\mathrm{V}}, \quad \mathrm{Ta}^{\mathrm{V}} ; \quad \mathrm{M}^{\prime}=\mathrm{Ti}^{\mathrm{II}}, \quad \mathrm{V}^{\mathrm{III}}\right)$ and investigated oxidative deintercalation of potassium using chlorine. Typically deintercalation proceeds as follows:

$$
\begin{aligned}
& \mathrm{KNb}_{0.5} \mathrm{Ti}_{0.5} \mathrm{OPO}_{4}+1 / 4 \mathrm{Cl}_{2} \rightarrow \\
& \mathrm{K}_{0.5} \mathrm{Nb}^{\mathrm{V}}{ }_{0.5} \mathrm{Ti}^{\cdot \mathrm{IV}}{ }_{0.5} \mathrm{OPO}_{4}+1 / 2 \mathrm{KCl}
\end{aligned}
$$

giving new KTP analogs. While the parent materials do not show SHG of $1064 \mathrm{~nm}$ radiation, the deintercalation products do show a SHG response. Both $\mathrm{K}_{0.5} \mathrm{Nb}^{\mathrm{V}}{ }_{0.5} \mathrm{Ti}^{\mathrm{IV}}{ }_{0.5} \mathrm{OPO}_{4}$ and $\mathrm{K}_{0.5} \mathrm{Ta}^{\mathrm{V}}{ }_{0.5} \mathrm{Ti}^{\mathrm{IV}_{0.5}} \mathrm{OPO}_{4}$ prepared by this route show powder SHG intensities of $532 \mathrm{~nm}$ radiation comparable to that of KTP. The synthesis of these new KTP analogs reveals the importance of $d^{0}$ cations towards determining the SHG property of KTP and its derivatives.

By using a similar strategy, we synthesized a new fresnoite oxide $\mathrm{Ba}_{1.5} \mathrm{VOSi}_{2} \mathrm{O}_{7}$, from $\mathrm{Ba}_{2} \mathrm{VOSi}_{2} \mathrm{O}_{7}$ by the deintercalation ${ }^{36} \mathrm{Ba}_{2} \mathrm{VOSi}_{2} \mathrm{O}_{7}+1 / 2 \mathrm{Br}_{2} \rightarrow \mathrm{Ba}_{1.5}$ $\mathrm{VOSi}_{2} \mathrm{O}_{7}+1 / 2 \mathrm{BaBr}_{2}$. While the parent $\mathrm{Ba}_{2} \mathrm{VOSi}_{2} \mathrm{O}_{7}$ is not SHG active, the oxidized material $\mathrm{Ba}_{1.5}$ $\mathrm{VOSi}_{2} \mathrm{O}_{7}$ exhibits a strong $\mathrm{SHG}$ activity. The framework of fresnoite (figure 3 ) is related to that of $\mathrm{K}_{2}(\mathrm{NbO})_{2} \mathrm{Si}_{4} \mathrm{O}_{12}$ (figure 3 ), an original NLO material synthesized by Tournox and co-workers. ${ }^{37}$

Novel redox reactivity has been revealed in the reaction of $\mathrm{La}_{2} \mathrm{CuO}_{4}$ with $\mathrm{VO}_{2}$ and $\mathrm{MoO}_{2}{ }^{38}$ Thus, in the reaction between $\mathrm{La}_{2} \mathrm{CuO}_{4}$ and $\mathrm{VO}_{2}$, the products are $\mathrm{LaVO}_{4}$ and $\mathrm{LaCuO}_{2}$ (delafossite structure), clearly indicating that the reaction involves the redox process $\mathrm{Cu}^{\mathrm{II}}+\mathrm{V}^{\mathrm{IV}} \rightarrow \mathrm{Cu}^{\mathrm{I}}+\mathrm{V}^{\mathrm{V}}$. Similarly, the reaction between $\mathrm{La}_{2} \mathrm{CuO}_{4}$ and $\mathrm{MoO}_{2}$ yielding $\mathrm{La}_{2} \mathrm{MoO}_{6}$ and $\mathrm{Cu}$ metal as products, also appears to be driven by the redox process $\mathrm{Cu}^{\mathrm{II}}+\mathrm{Mo}^{\mathrm{IV}} \rightarrow$ $\mathrm{Cu}^{0}+\mathrm{Mo}^{\mathrm{VI}}$. In both these cases, the redox reactivity between $\mathrm{V}^{\mathrm{IV}} / \mathrm{Mo}^{\mathrm{IV}}$ and $\mathrm{Cu}^{\mathrm{II}}$ is more important than the acidity of $\mathrm{VO}_{2} / \mathrm{MoO}_{2}$ in determining the nature of the final products obtained. Significantly, both the redox reactions, $\mathrm{Mo}^{\mathrm{IV}}+\mathrm{Cu}^{\mathrm{II}} \rightarrow \mathrm{Mo}^{\mathrm{VI}}+\mathrm{Cu}^{0}$ and $\mathrm{V}^{\mathrm{IV}}+\mathrm{Cu}^{\mathrm{II}} \rightarrow \mathrm{V}^{\mathrm{V}}+\mathrm{Cu}^{\mathrm{I}}$, are not expected to proceed towards the right on the basis of solution reduction potential data ${ }^{17}\left(\mathrm{Mo}^{\mathrm{VI}} / \mathrm{Mo}^{\mathrm{IV}}, 0.646 \mathrm{~V} ; \mathrm{V}^{\mathrm{V}} / \mathrm{V}^{\mathrm{IV}}\right.$, $\left.1.000 \mathrm{~V} ; \mathrm{Cu}^{\mathrm{II}} / \mathrm{Cu}^{\mathrm{I}}, 0.159 \mathrm{~V} ; \mathrm{Cu}^{\mathrm{II}} / \mathrm{Cu}^{0}, 0.340 \mathrm{~V}\right)$. Presumably, these redox processes become favourable in the solid state at high temperatures.

Redox competition between transition metal ions in mixed metal oxides is important in the design of new magnetic and metallic oxides (spintronic materials). Thus, $\mathrm{A}_{2} \mathrm{FeReO}_{6}(\mathrm{~A}=\mathrm{Ca}, \mathrm{Sr}, \mathrm{Ba})$ (figure 4), involves the redox process.

$$
\begin{aligned}
& \mathrm{Fe}^{\mathrm{II}}+\mathrm{Re}^{\mathrm{VI}} \leftrightarrow \mathrm{Fe}^{\mathrm{III}}+\mathrm{Re}^{\mathrm{V}} \\
& 3 d^{6} \quad 5 d^{1} \quad 3 d^{5} 5 d^{2}
\end{aligned}
$$

which is biased towards the right for the calcium, while it is degenerate for strontium and barium. Accordingly, we find that $\mathrm{Ba}_{2} \mathrm{FeReO}_{6}$ has a metallic ground state, while $\mathrm{Ca}_{2} \mathrm{FeReO}_{6}$ has an insulating ground state. ${ }^{39} \mathrm{~A}$ similar redox competition between $\mathrm{M}^{\mathrm{III} / \mathrm{IV}}(\mathrm{M}=\mathrm{Co}, \mathrm{Fe})$ and $\mathrm{Re}^{\mathrm{VII} / \mathrm{VI}}$ gives rise to ferrimagnetism in the perovskite-based oxides, $\mathrm{Sr}_{4} \mathrm{M}_{3}$ $\mathrm{ReO}_{12}(\mathrm{M}=\mathrm{Co}, \mathrm{Fe}){ }^{39 \mathrm{c}}$ Another interesting example of this kind is provided by $\mathrm{LaAMnRuO}_{6}(\mathrm{~A}=\mathrm{Ca}$, 
$\mathrm{Sr}$, Ba) where the redox process $\mathrm{Mn}^{\mathrm{III}} / \mathrm{Ru}^{\mathrm{IV}} \leftrightarrow$ $\mathrm{Mn}^{\mathrm{IV}} / \mathrm{Ru}^{\mathrm{II}}$ is likely important for the ferromagnetic and highly conducting properties. ${ }^{40}$

Determination of oxidation states of metal atoms in transition metal compounds is an important issue that is often accomplished by titrimetric procedures based on oxidation-reduction reactions. ${ }^{41}$ Thus, mixed valences of transition metals such as molybdenum, vanadium, manganese and copper in several perovskites and related oxides have been quantitatively determined by appropriate redox titrations. The issue is particularly relevant for the determination of hole-concentration in superconducting cuprates. Titrations employing $\mathrm{I}^{-}$or $\mathrm{Fe}^{2+}$ as reducing agents are commonly resorted to for this purpose. ${ }^{42}$ Thus treatment of a superconducting cuprate with an $\mathrm{I}^{-}$solution liberates $\mathrm{I}_{2}$ corresponding to the mixed oxidation state of $\mathrm{Cu}^{2+/ 3+}$ providing a quantitative method to find out the excess hole concentration $\left(\mathrm{Cu}^{3+}\right)$. This method however could not be used directly for the thallium-cuprates because of the interference of $\mathrm{Tl}^{\mathrm{III}}$ in iodometry. We have resolved the issue $^{43}$ by realizing the differences in redox potentials of $\mathrm{Cu}^{\mathrm{III}} / \mathrm{Cu}^{\mathrm{II}}, \mathrm{Tl}^{\mathrm{III}} / \mathrm{Tl}^{\mathrm{I}}$ versus $\mathrm{I}_{2} / \mathrm{I}^{-}$and $\mathrm{Br}_{2} / \mathrm{Br}^{-}$. Although the exact reduction potential of $\mathrm{Cu}^{\mathrm{III}} / \mathrm{Cu}^{\mathrm{II}}$ is not available in the literature, we perceived that it should be higher than the value for $\mathrm{Tl}^{\mathrm{III}} \mathrm{Tl}^{\mathrm{I}}$. Accordingly, $\mathrm{Br}^{-}$would selectively react with $\mathrm{Cu}^{\text {III }}$ liberating $\mathrm{Br}_{2}$, while $\mathrm{I}^{-}$would react with both $\mathrm{Cu}^{\mathrm{III}}$ and $\mathrm{Tl}^{\mathrm{III}}$. These considerations have enabled us to develop a new titrimetric procedure for the determination of hole-concentration in thallium-cuprate superconductors. ${ }^{43}$

Oxidation reactions involving thiosulphate, permanganate, dichromate, periodate and persulphate are well known in inorganic chemistry. An unusual instance of reduction involving phosphate, arsenate and antimonate in the solid state has enabled us to develop a convenient route for the synthesis of transition metal pnictides. ${ }^{44}$ While reduction of phosphate to $\mathrm{P}^{3-}$ is unthinkable in solution medium, we found that several transition metal phosphates in the solid state undergo direct reduction in hydrogen at relatively low temperatures $\left(400-1000^{\circ} \mathrm{C}\right)$ to the corresponding phosphides. For example, $\mathrm{MoOPO}_{4}$, $\mathrm{FePO}_{4}$ and $\mathrm{NH}_{4} \mathrm{MPO}_{4}(\mathrm{M}=\mathrm{Fe}, \mathrm{Co}, \mathrm{Ni})$ undergo reduction to yield $\mathrm{MoP}, \mathrm{Fe}_{2} \mathrm{P}, \mathrm{FeP}, \mathrm{Co}_{2} \mathrm{P}$ and $\mathrm{Ni}_{2} \mathrm{P}$ respectively. A typical reduction reaction of this kind is $\mathrm{MoOPO}_{4}+5 \mathrm{H}_{2} \rightarrow \mathrm{MoP}+5 \mathrm{H}_{2} \mathrm{O}$. A similar and more facile reduction of metal arsenates and antimonates enabled us to synthesize a wide variety of transition metal arsenides and antimonides as well. Interestingly, the reduction route is applicable only to those metals that are less electropositive than hydrogen, suggesting the involvement of metal $d$ states in the reduction process. A redox cycle between $\mathrm{SO}_{4}^{2-}$ and $\mathrm{S}^{2-}$ has recently been reported for $\mathrm{La}_{2} \mathrm{O}_{2} \mathrm{SO}_{4}, \mathrm{La}_{2} \mathrm{O}_{2} \mathrm{SO}_{4}+4 \mathrm{H}_{2} \leftrightarrow \mathrm{La}_{2} \mathrm{O}_{2} \mathrm{~S}+4 \mathrm{H}_{2} \mathrm{O}$, providing a convenient oxygen storage medium. ${ }^{45}$

\subsection{Crystal field theory}

Crystal field theory constitutes a corner-stone of inorganic chemistry that provided the basis for understanding several aspects of transition metal chemistry: structure, stability, coordination geometry, spectroscopy and magnetism. ${ }^{17}$ Concepts such as ligand field stabilization energy, low spin - high spin, electronic configuration, octahedral versus tetrahedral (square planar and other) geometries, which are relevant to the inorganic chemistry of transition metal complexes find application in the solid state chemistry as well. Ideas such as $\mathrm{F}^{-}$and $\mathrm{H}_{2} \mathrm{O}$ are weak ligands that stabilize high spin octahedral complexes, are directly applicable to solid state chemistry of $3 \mathrm{~d}$ transition metals. Thus, all the $\mathrm{MF}_{2}$ and $\mathrm{MO}(\mathrm{M}=$ divalent $\mathrm{Mn}$, $\mathrm{Fe}, \mathrm{Co}, \mathrm{Ni})$ are all high spin, whereas the disulfides $\mathrm{MS}_{2}$ are all low spin. These considerations together with ligand field stabilization energies have found an early application in rationalizing normal versus inverse spinel structures. ${ }^{46} \mathrm{Fe}_{3} \mathrm{O}_{4}$ and $\mathrm{NiFe}_{2} \mathrm{O}_{4}$ are ferrimagnetic inverse spinels, while $\mathrm{ZnFe}_{2} \mathrm{O}_{4}$ and $\mathrm{MnFe}_{2} \mathrm{O}_{4}$ possess normal spinel structures, reflecting the equal preference of $\mathrm{Fe}^{\mathrm{III}}$ and $\mathrm{Mn}^{\mathrm{II}}\left(3 d^{5}\right)$ for both octahedral and tetrahedral coordination geometries. Another manifestation of this preference is the brownmillerite structure (figure 5) of $\mathrm{Ca}_{2} \mathrm{Fe}_{2} \mathrm{O}_{5}$ where $\mathrm{Fe}^{\mathrm{III}}$ occurs in both octahedral and tetrahedral coordination geometries. $\mathrm{Co}^{\mathrm{II}}\left(3 d^{7}\right)$ and $\mathrm{Ni}^{\mathrm{II}}\left(3 d^{8}\right)$ exhibit octahedral geometry in high spin complexes. However the $d^{7} \mathrm{Co}^{\mathrm{II}}$ has a distinct tetrahedral preference and $d^{8} \mathrm{Ni}^{\mathrm{II}}$ has a distinct square planar preference with increasing metal-ligand covalency. Recognition of this difference between $\mathrm{Co}^{\mathrm{II}}$ and $\mathrm{Ni}^{\mathrm{II}}$ has enabled us to synthesize $\mathrm{La}_{2} \mathrm{Co}_{2} \mathrm{O}_{5}$ in the brownmillerite structure and $\mathrm{La}_{2} \mathrm{Ni}_{2} \mathrm{O}_{5}$ in a special structure (figure 5) that contains $\mathrm{Ni}^{\mathrm{II}}$ both in octahedral and square planar geometries. ${ }^{47}$ The synthesis of these two oxides has been achieved by a mild reduction of the corresponding $\mathrm{LaMO}_{3}(\mathrm{M}=\mathrm{Co}, \mathrm{Ni})$ perovskites. In contrast to the brownmillerite structure of $\mathrm{Ca}_{2} \mathrm{Fe}_{2} \mathrm{O}_{5}$ and $\mathrm{La}_{2} \mathrm{Co}_{2} \mathrm{O}_{5}, \mathrm{Ca}_{2} \mathrm{Mn}_{2} \mathrm{O}_{5}$ (figure 5) and $\mathrm{Ca}_{2} \mathrm{Co}_{2} \mathrm{O}_{5}$ 


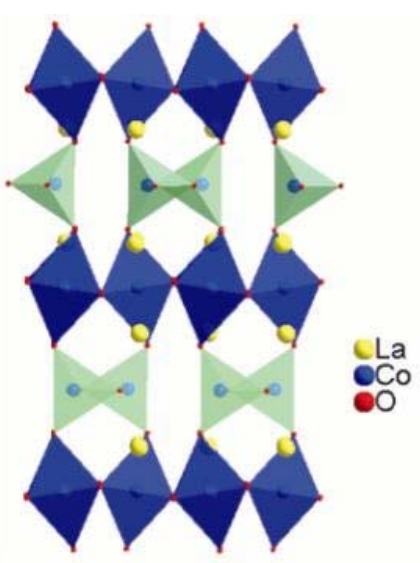

(a)

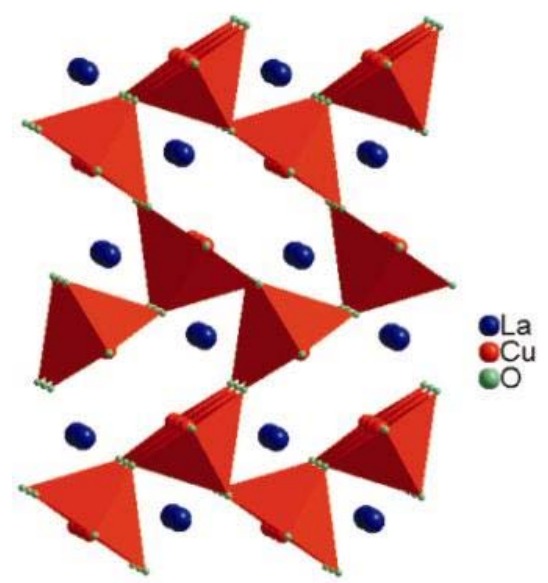

(c)

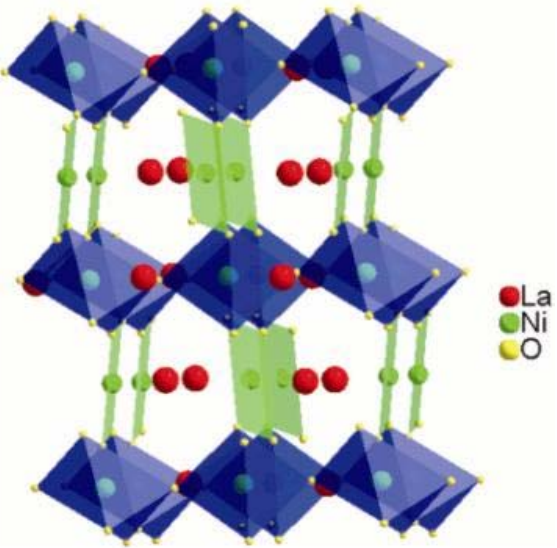

(b)

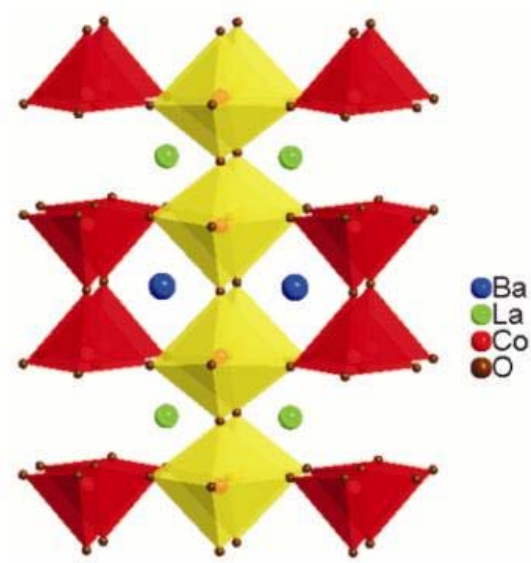

(d)

Figure 5. Crystal structures of defect perovskite oxides: (a) $\mathrm{La}_{2} \mathrm{Co}_{2} \mathrm{O}_{5}$ (brownmillerite structure), (b) $\mathrm{La}_{2} \mathrm{Ni}_{2} \mathrm{O}_{5}$, (c) $\mathrm{La}_{2} \mathrm{Cu}_{2} \mathrm{O}_{5} / \mathrm{Ca}_{2} \mathrm{Mn}_{2} \mathrm{O}_{5}$ and (d) $\mathrm{LnBaCo}_{2} \mathrm{O}_{5.5}$ (Ln = rare earth).

possess unique structures based on square pyramidally coordinated $\mathrm{Mn}^{\mathrm{III}}$ and $\mathrm{Co}^{\mathrm{III}} . \mathrm{La}_{2} \mathrm{Cu}_{2} \mathrm{O}_{5}$ (figure 5) is isostructural with $\mathrm{Ca}_{2} \mathrm{Mn}_{2} \mathrm{O}_{5}$, wherein $\mathrm{Cu}^{2+}$ is square pyramidally coordinated. ${ }^{48,49}$ The distinct preference of $\mathrm{Mn}^{\mathrm{III}}\left(3 d^{4}\right)$ and $\mathrm{Cu}^{\mathrm{II}}\left(3 d^{9}\right)$ to square pyramidal geometry is a manifestation of the Jahn-Teller effect associated with these configurations (see later).

Perovskite $\mathrm{LaCoO}_{3}$ is a unique oxide that defied an understanding of its properties for several years, ${ }^{50}$ mainly because of the possibility of $\mathrm{Co}^{\mathrm{III}}\left(3 d^{6}\right)$ to exist in multiple spin states. Normally, $\mathrm{Co}^{\mathrm{III}}\left(3 d^{6}\right)$ is expected to exhibit low spin (LS) $\mathrm{t}_{2 \mathrm{~g}}{ }^{6} \mathrm{e}_{\mathrm{g}}{ }^{0}(\mathrm{~S}=0)$ state. Indeed $\mathrm{LaCoO}_{3}$ does exist in this state at lowest temperatures, but changes to the high spin (HS) $t_{2 \mathrm{~g}}{ }^{4} e_{g}{ }^{2}(\mathrm{~S}=2)$ configuration at higher temperatures. But in view of the small energy difference between the LS and HS states, an intermediate spin state (IS) $t_{2 g}{ }^{5} e_{g}{ }^{1}(\mathrm{~S}=1)$ is stabilized in the interval $35-100 \mathrm{~K}$.
The occurrence of Jahn-Teller distortion as well as orbital ordering associated with the IS state and the possibility of ferromagnetism are manifestations of these changes in the electronic configuration of $\mathrm{Co}^{\mathrm{III}}$ in this oxide.

$\mathrm{LnBaCO}_{2} \mathrm{O}_{5.5}(\mathrm{Ln}=$ lanthanide) (figure 5) constitute an interesting series of cobalt oxides which exhibit a metal-insulator transition coupled with spin state transition. ${ }^{51}$ In these compounds, cobalt exists both in octahedral and square pyramidal geometry as alternating rows in an oxygen deficient perovskite structure. The octahedral cobalt exhibits a spin state transition from LS $\rightarrow \mathrm{HS}$, while the pyramidal cobalt exists in the IS state. The spin state transition around $300-350 \mathrm{~K}$ coincides with the insulatormetal transition.

Perovskite-related ruthenium oxides are a special series of oxides exhibiting remarkable properties. ${ }^{52}$ $\mathrm{SrRuO}_{3}$, a three-dimensional perovskite, is a metallic 


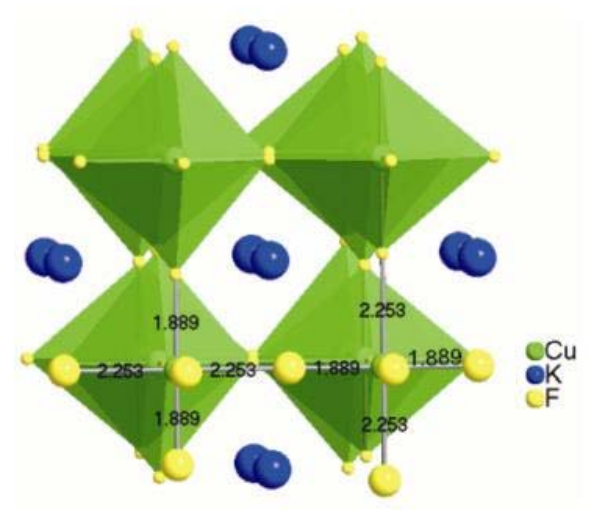

(a)

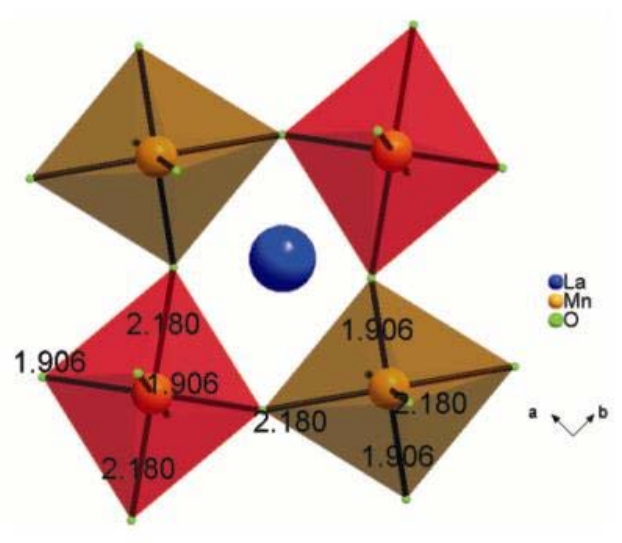

(b)

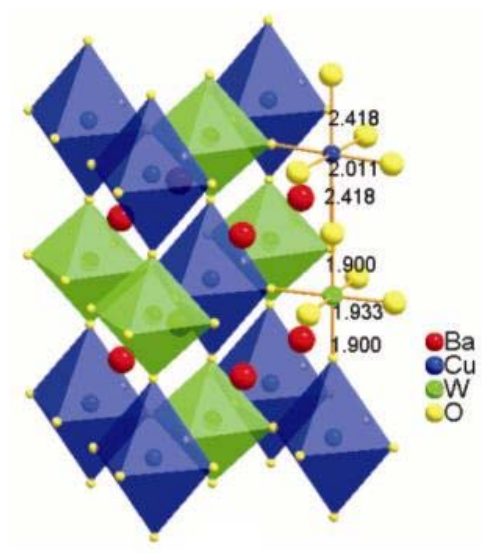

(c)

Figure 6. Crystal structures of (a) $\mathrm{KCuF}_{3}$, (b) $\mathrm{LaMnO}_{3}$ and (c) $\mathrm{Ba}_{2} \mathrm{CuWO}_{6}$ showing cooperative Jahn-Teller distortions.

ferromagnet with $T_{c}=160 \mathrm{~K}$, whereas $\mathrm{Sr}_{2} \mathrm{RuO}_{4}$ containing a single sheet of $\mathrm{RuO}_{6}$ octahedra $\left(\mathrm{K}_{2} \mathrm{NiF}_{4}\right.$ structure) is a spin triplet superconductor. In both the cases, ruthenium exists in the tetravalent state, $\mathrm{Ru}^{\mathrm{IV}}\left(4 d^{4}\right)$. This dramatic change in the properties as one goes from $\mathrm{SrRuO}_{3}$ to $\mathrm{Sr}_{2} \mathrm{RuO}_{4}$ through the intermediate $\mathrm{Sr}_{n+1} \mathrm{Ru}_{n} \mathrm{O}_{3 n+1}$ members has been suspected to arise from a high spin to low spin transition $^{53}$ of $\mathrm{Ru}^{\mathrm{IV}}$, that is, $\mathrm{Ru}^{\mathrm{IV}}$, is believed to exist in high spin state in $\mathrm{Sr}_{2} \mathrm{RuO}_{4}$ and low spin state in $\mathrm{SrRuO}_{3}$. We found evidence for the existence of high spin $\mathrm{Ru}^{\mathrm{IV}}$ together with high spin $\mathrm{Mn}^{\mathrm{III}}$ in $\mathrm{LaAMnRuO}_{6}$ perovskites $(\mathrm{A}=\mathrm{Ca}, \mathrm{Sr}, \mathrm{Ba})$ where the strong hybridization between $\mathrm{Mn}^{\mathrm{III}}$ and $\mathrm{Ru}^{\mathrm{IV}} d$ electrons results in a remarkable long-range ferromagnetism and absence of orbital ordering. ${ }^{54}$

\subsection{Jahn-Teller distortions}

Structural distortions due to Jahn-Teller effect are common in inorganic chemistry ${ }^{17,55}$ and solid state chemistry, ${ }^{18,56}$ whenever a set of degenerate orbitals is unevenly occupied by electrons. In principle, for octahedral geometry, uneven orbital occupancy arises when the $t_{2 g}$ orbitals have one, two, four or five electrons or when the $e_{g}$ orbitals are occupied by one or three electrons. In practice, distortions arising from uneven occupation of $t_{2 g}$ orbitals are rather small and difficult to observe: but the effect is generally pronounced with $e_{g}$ orbitals which are $\sigma$-bonding. Jahn-Teller distortions are most pronounced with $\mathrm{Cu}^{\mathrm{II}}\left(3 d^{9}\right), \mathrm{Mn}^{\mathrm{III}}\left(3 d^{4}\right)$ and $\mathrm{Cr}^{\mathrm{II}}\left(3 d^{4}\right)$ (high spin) configurations. A distortion is generally seen as tetragonal elongation of the octahedron so as to produce four short and two long bonds around an octahedron. In the solid state, the distortions around each ion are accommodated in such a way as to result in cooperatively distorted structures along with orbital ordering. Cooperative Jahn-Teller effect together with orbital ordering is found in the crystal structures of $\mathrm{KCuF}_{3} / \mathrm{RbCuF}_{3} \quad(I 4 m c m), \quad \mathrm{LaMnO}_{3} \quad(P n m a)$ and $\mathrm{Ba}_{2} \mathrm{CuWO}_{6}(\mathrm{I} / \mathrm{m})$ (figure 6).

In contrast to these conventional Jahn-Teller distortions associated with unevenly occupied $d$-shell [first order Jahn-Teller (FOJT) effect], distortions of a different kind involving $\mathrm{d}^{0}$ cations at octahedral sites are also known. These are called second order Jahn-Teller (SOJT) distortions. ${ }^{57}$ A SOJT distortion occurs when the energy gap between the cationic LUMO states and the anionic HOMO states is small and there is a symmetry allowed distortive mode that permits mixing of HOMO and LUMO states. Typically, this distortion operates in several metal oxides containing $d^{0}$ cations such as $\mathrm{Ti}^{\mathrm{IV}}, \mathrm{Nb}^{\mathrm{V}}, \mathrm{Mo}^{\mathrm{VI}}$ and $\mathrm{W}^{\mathrm{VI}}$. The consequences of SOJT distortion for the structure and properties of $d^{0}$ transition metal oxides are tremendous. Thus, the distorted antiferroelectric $\mathrm{WO}_{3}$ structure, layered $\mathrm{MoO}_{3}$ structure (figure 1) and the various ferroelectric structures of $\mathrm{BaTiO}_{3}$ and $\mathrm{KNbO}_{3}$ could be directly traced to SOJT effect.

We have explored at some length ${ }^{57 a}$ the consequences of SOJT effect towards the structure and properties of several $d^{0}$ transition metal oxides, resulting in a variety of new materials. For instance, the charge-coupled replacement, $2 \mathrm{Sr}^{2+} \rightarrow \mathrm{Na}^{+} / \mathrm{K}^{+}+$ $\mathrm{La}^{3+}$, has transformed $\mathrm{Sr}_{2} \mathrm{TiO}_{4}$ and $\mathrm{Sr}_{4} \mathrm{Ti}_{3} \mathrm{O}_{10}$ into isotypic layered oxides, $\mathrm{NaLaTiO}_{4}$ and $\mathrm{K}_{2} \mathrm{La}_{2} \mathrm{Ti}_{3} \mathrm{O}_{10}$, 


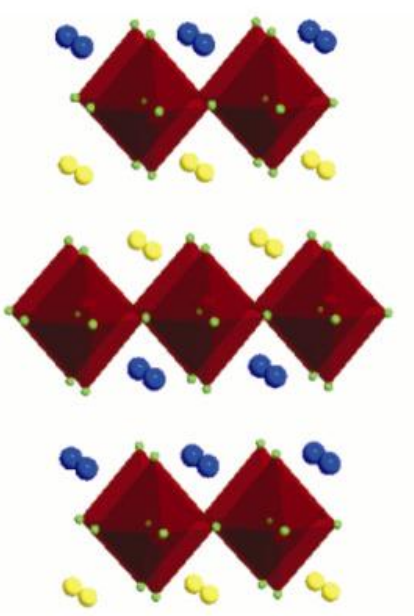

(a)

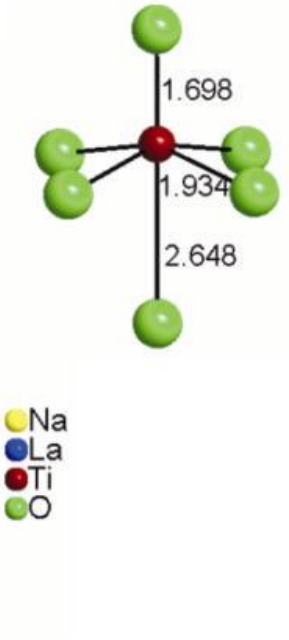

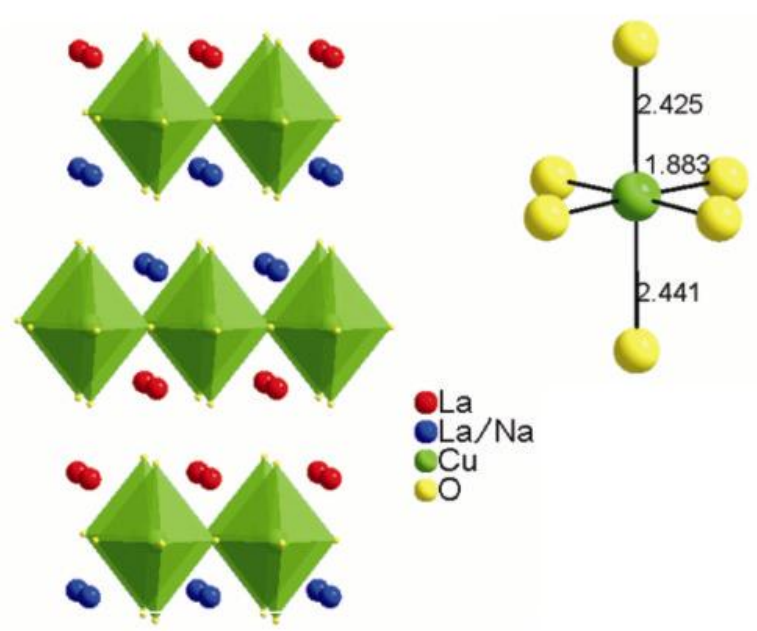

(b)

Figure 7. A comparison of the SOJT and FOJT distortions in the crystal structures of (a) $\mathrm{NaLaTiO}_{4}$ and (b) $\mathrm{La}_{2-x} \mathrm{Na}_{x} \mathrm{CuO}_{4}$. The distortion around $\mathrm{TiO}_{6}$ and $\mathrm{CuO}_{6}$ octahedra are shown separately (bond lengths in $\AA$ ).

where the unique ordering of monovalent alkali metal atoms in the interlayer space (figure 7) gives rise to novel interlayer chemistry and the possibility of ion exchange. ${ }^{27}$ The unique ordering pattern of the alkali and lanthanum in these materials is clearly dictated by the SOJT distortions of $\mathrm{TiO}_{6}$ octahedra.

Interestingly, a similar alkali metal ordering has been reported in the superconducting $\mathrm{La}_{2-x} \mathrm{M}_{x} \mathrm{CuO}_{4}$ $(\mathrm{M}=\mathrm{Na}, \mathrm{K})$ where the alkali metal ions are ordered in the alternate layers ${ }^{58}$ between the $\mathrm{Cu}-\mathrm{O}$ sheets in the sequence $[\mathrm{La}-\mathrm{O}]_{2}-\mathrm{CuO}_{2}-[(\mathrm{La} / \mathrm{Na})-\mathrm{O}]_{2}-\mathrm{CuO}_{2}$ (figure 7). This is in contrast to the alkaline earth metaldoped lanthanum copper oxides such as $\mathrm{La}_{2-x}$ $\mathrm{Sr}_{x} \mathrm{CuO}_{4}$, where the strontium randomly substitutes for lanthanum. Clearly, the ordering is induced by the FOJT of the $\mathrm{CuO}_{6}$ octahedra resulting in unequal apical $\mathrm{Cu}-\mathrm{O}$ bonds. The similarity of this distortion to that of $\mathrm{TiO}_{6}$ octahedron ${ }^{59}$ in $\mathrm{NaLaTiO}_{4}$ is indeed striking. This suggested to us the possibility of combining $\mathrm{Cu}^{\mathrm{II}}$ and $\mathrm{Ti}^{\mathrm{IV}}$ together in perovskite related oxides where the FOJT of $\mathrm{CuO}_{6}$ and the SOJT of $\mathrm{TiO}_{6}$ could synergistically couple to produce new materials and properties. Accordingly, we synthesized two new quadruple perovskites, ${ }^{60} \mathrm{Sr}_{2} \mathrm{La}_{2}$ $\mathrm{CuTi}_{3} \mathrm{O}_{12}$ and $\mathrm{Ca}_{2} \mathrm{La}_{2} \mathrm{CuTi}_{3} \mathrm{O}_{12}$, by solid state metathesis reactions between the layered perovskites $\mathrm{K}_{2} \mathrm{La}_{2} \mathrm{Ti}_{3} \mathrm{O}_{10}$ and $\mathrm{A}_{2} \mathrm{CuO}_{2} \mathrm{Cl}_{2}(\mathrm{~A}=\mathrm{Sr}, \mathrm{Ca})$. The metathesis reaction,

$$
\mathrm{K}_{2} \mathrm{La}_{2} \mathrm{Ti}_{3} \mathrm{O}_{10}+\mathrm{A}_{2} \mathrm{CuO}_{2} \mathrm{Cl}_{2} \rightarrow
$$

$$
\mathrm{A}_{2} \mathrm{La}_{2} \mathrm{CuTi}_{3} \mathrm{O}_{12}+2 \mathrm{KCl} \text {, }
$$

yields novel quadruple perovskite oxides where $\left[\mathrm{ACuO}_{2}\right]^{2+}$ and $\left[\mathrm{La}_{2} \mathrm{Ti}_{3} \mathrm{O}_{10}\right]^{2-}$ slabs stack alternately along the $c$-axis. The $\mathrm{TiO}_{6}$ and $\mathrm{CuO}_{6}$ octahedra retain their structural identity in the products (figure 8).

Similarly, the reaction between $\mathrm{NaLaTiO}_{4}$ and $\mathrm{Ca}_{2} \mathrm{CuO}_{2} \mathrm{Cl}_{2}$ yielded a new oxide ${ }^{61} \mathrm{Ca}_{2} \mathrm{La}_{2} \mathrm{CuTi}_{2} \mathrm{O}_{10}$, where again the individual structural features and the associated Jahn-Teller distortions around copper and titanium are preserved (figure 9). These transformations of layered perovskite oxides open up the possibility of creating new materials that combine metal atoms exhibiting FOJT and SOJT.

Strong FOJT in $\mathrm{Cu}^{\mathrm{II}}$-oxides which is a consequence of the interplay between electronic degeneracy and coupling to the lattice has been implicated to be a novel glue for electron pairing in cuprate superconductors. The consequences of this idea that lead to unconventional isotope effects and complex pairing symmetry related to multi-band superconductivity have recently been explored in an effort to find the mechanism of high $T_{C}$ superconductivity in these materials. ${ }^{62}$

\subsection{Mixed valence, electron transfer, inner/outer sphere mechanisms}

Ideas relating to mixed valency, electron transfer and inner/outer sphere mechanisms which are largely developed in the context of inorganic chemistry find widespread application in solid state/materials 


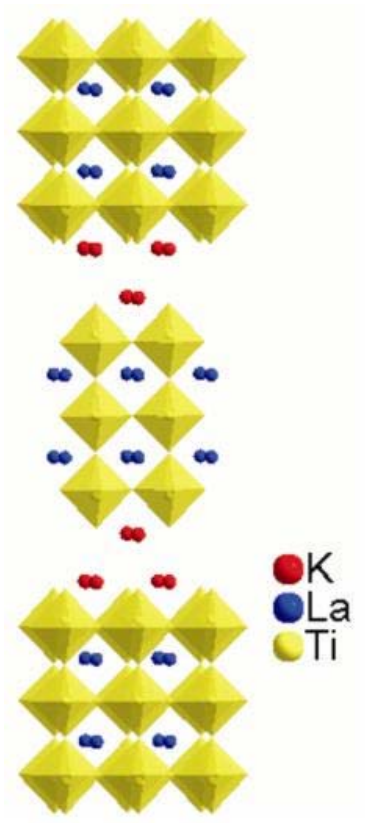

(a)

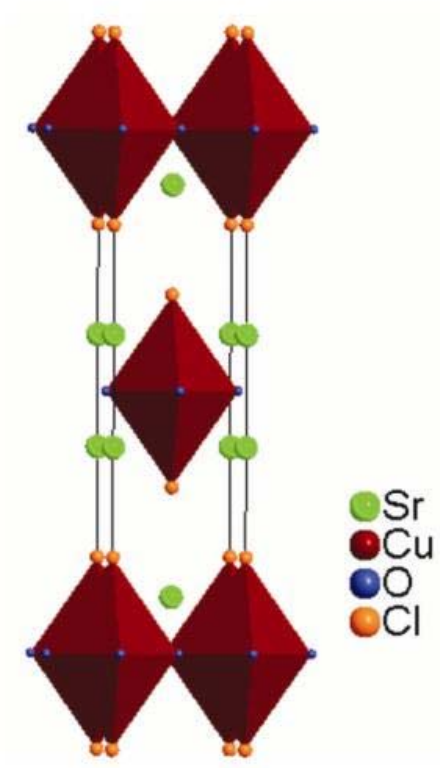

(b)

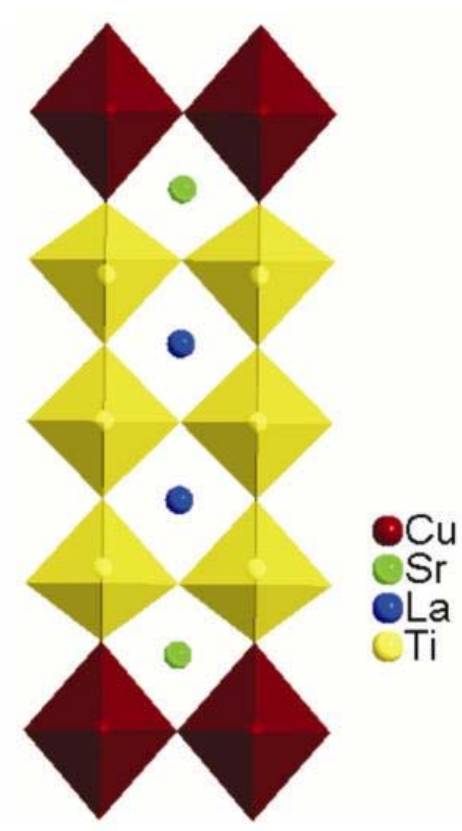

(c)

Figure 8. Crystal structures of (a) $\mathrm{K}_{2} \mathrm{La}_{2} \mathrm{Ti}_{3} \mathrm{O}_{10}$, (b) $\mathrm{Sr}_{2} \mathrm{CuO}_{2} \mathrm{Cl}_{2}$ and (c) $\mathrm{Sr}_{2} \mathrm{La}_{2} \mathrm{CuTi}_{3} \mathrm{O}_{12}$.

chemistry. The classification of mixed valent compounds into Classes I, II and III provided by Robin and Day 40 years ago is quite relevant to today's materials chemistry. ${ }^{63}$ The classification is based on the strength of the electronic interaction and the distinguishability or otherwise of the two states. Thus $\mathrm{AgO}$ which is actually $\mathrm{Ag}^{\mathrm{I}} \mathrm{Ag}^{\mathrm{III}} \mathrm{O}_{2}$ and $\mathrm{CsAuCl}_{3}$ which is $\mathrm{Cs}_{2} \mathrm{Au}^{\mathrm{I}} \mathrm{Au}^{\mathrm{III}} \mathrm{Cl}_{6}$, where the monovalent $\mathrm{Ag} / \mathrm{Au}$ are linearly coordinated, are typical Class I compounds, because the environments of the lower and higher oxidation states of the metal atoms are quite different and there is no obvious electronic interaction between them. A more recent example of Class I mixed valency would be $\mathrm{YBa}_{2} \mathrm{Cu}^{\mathrm{I}} \mathrm{Cu}_{2}{ }^{\mathrm{II}} \mathrm{O}_{6}$ (figure 10), which is the non-superconducting parent of the high $T_{C}$ superconductor $\mathrm{YBa}_{2} \mathrm{Cu}_{3} \mathrm{O}_{7}$. On the other hand, $\mathrm{Na}_{x} \mathrm{WO}_{3}$, superconducting $(\mathrm{K}, \mathrm{Ba}) \mathrm{BiO}_{3}$, $\mathrm{La}_{2-x} \mathrm{Sr}_{x} \mathrm{CuO}_{4}$ and $\mathrm{LiTi}_{2} \mathrm{O}_{4}$ are clear examples for Class III mixed valency, where the mixed valent metallic sites are indistinguishable and the electrons causing mixed valency are delocalized.

Between these two extremes lie a range of intermediate cases (Class II) wherein the environments of the two sites are distinguishable but not very different; in addition, the mixed valent electron(s) are localized on the vibrational time scale. A large number of mixed valent compounds belong to this category: $\mathrm{Fe}_{3} \mathrm{O}_{4}$ (magnetite), $\mathrm{Fe}^{\mathrm{II}} \mathrm{Fe}^{\mathrm{III}} \mathrm{OBO}_{3}$ (war- wickite) and the well known pyrazine-bridged $\mathrm{Ru}^{\mathrm{II}}-$ $\mathrm{Ru}^{\text {III }}$ amine complex (Creutz-Taube complex) belong to Class II type. Even $\mathrm{BaBiO}_{3}$ which is $\mathrm{Ba}_{2} \mathrm{Bi}^{\mathrm{III}} \mathrm{Bi}^{\mathrm{V}} \mathrm{O}_{6}$ could be regarded Class II type, because both $\mathrm{Bi}^{\mathrm{III}}$ and $\mathrm{Bi}^{\mathrm{V}}$ are distinguishable but octahedrally coordinated (figure 11) ${ }^{64}$ The boundary between Class II and Class III however is not well defined in many instances and transitions between the two could occur depending upon experimental variables. ${ }^{65}$

Mixed valency, especially of Class II and Class III type, involves electron transfer. Henry Taube in his pioneering work $^{66}$ established more than half a century ago that there are two different mechanisms for electron transfer reactions of transition metal complexes in solution. The transfer would be outer sphere if there is no change in the coordination sphere. On the other hand, the transfer would be inner sphere if there is a change in the coordination sphere of the redox centre. A classical example of an inner sphere electron transfer reaction is

$$
\begin{aligned}
& {\left[\mathrm{CoCl}\left(\mathrm{NH}_{3}\right)_{5}\right]^{2+}+\left[\mathrm{Cr}\left(\mathrm{OH}_{2}\right)_{6}\right]^{2+}+5 \mathrm{H}_{2} \mathrm{O}(\mathrm{l}) \rightarrow} \\
& {\left[\mathrm{Co}\left(\mathrm{OH}_{2}\right)_{6}\right]^{2+}+\left[\mathrm{CrCl}\left(\mathrm{OH}_{2}\right)_{5}\right]^{2+}+5 \mathrm{NH}_{3}}
\end{aligned}
$$

where the chloride initially bound to $\mathrm{Co}^{\mathrm{III}}$ is transferred to $\mathrm{Cr}^{\mathrm{II}}$ when the electron transfer occurs. On the other hand, outer sphere electron transfer occurs 


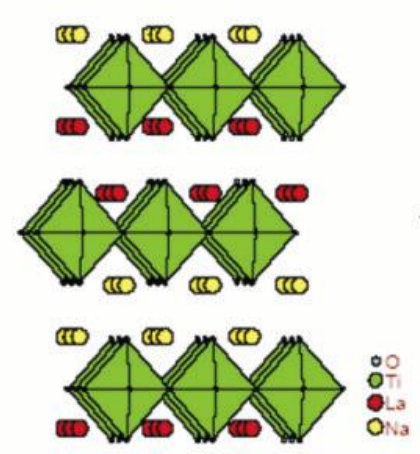

(a)

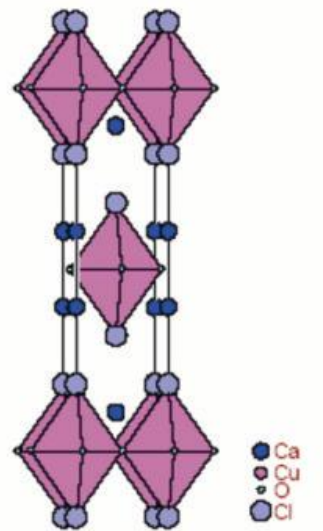

(b)

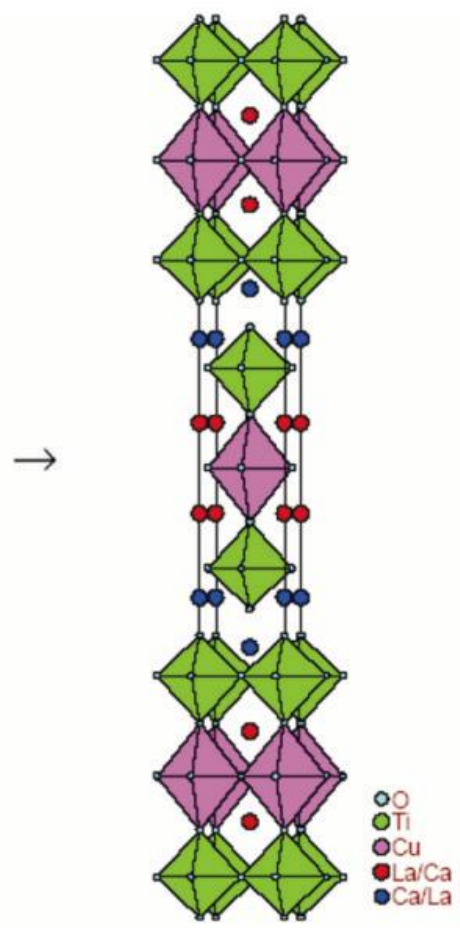

(c)

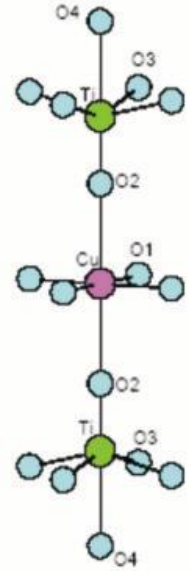

(d)

Figure 9. Schematic representation of the metathesis reaction between (a) $\mathrm{NaLaTiO}_{4}$ and (b) $\mathrm{Ca}_{2} \mathrm{Cu}_{2} \mathrm{O}_{2} \mathrm{Cl}_{2}$ yielding (c) $\mathrm{Ca}_{2} \mathrm{La}_{2} \mathrm{CuTi}_{2} \mathrm{O}_{10}$. (d) Shows the bonds in $\mathrm{TiO}_{6} / \mathrm{CuO}_{6}$ octahedra in (c).

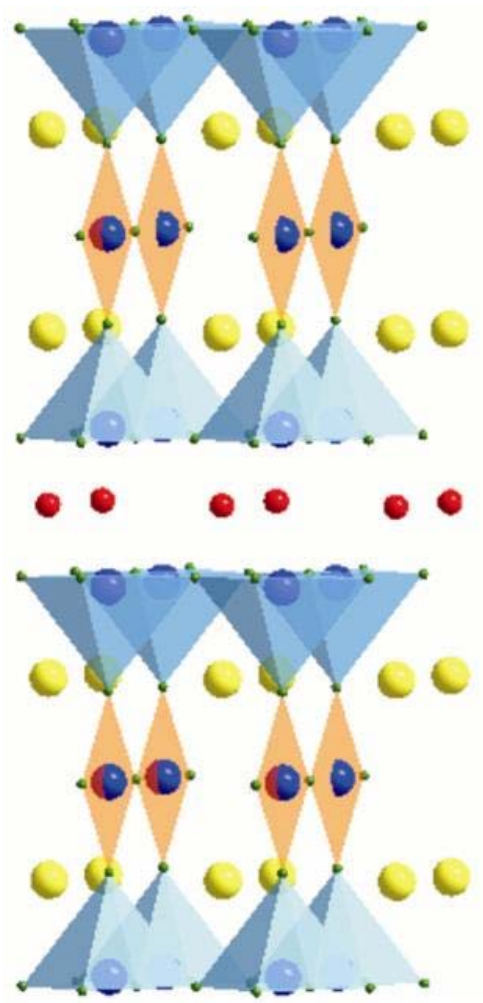

(a)
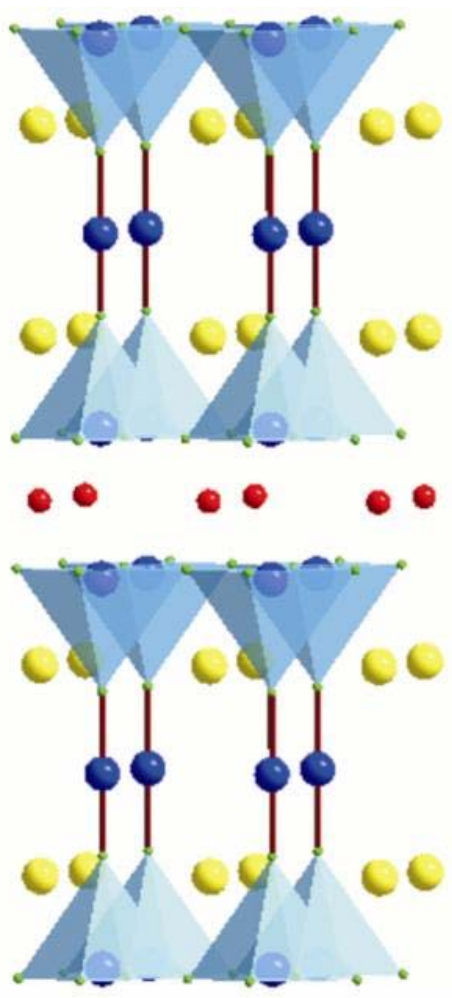

(b)

Figure 10. Crystal structures of (a) $\mathrm{YBa}_{2} \mathrm{Cu}_{3} \mathrm{O}_{7}$ and (b) $\mathrm{YBa}_{2} \mathrm{Cu}_{3} \mathrm{O}_{6}$. 


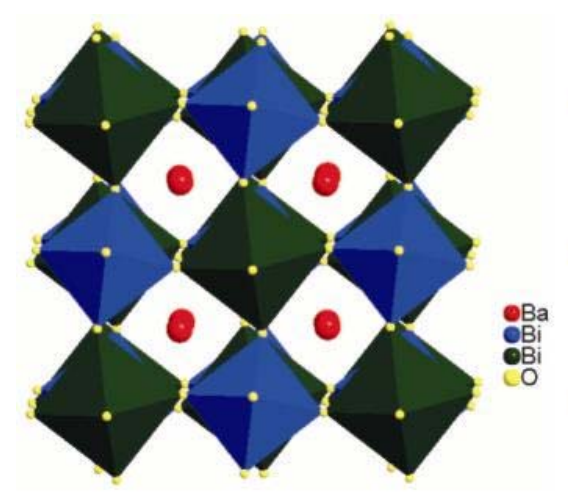

(a)

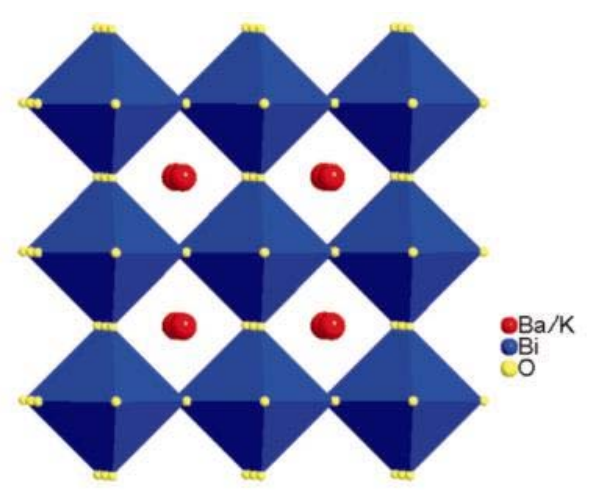

(b)

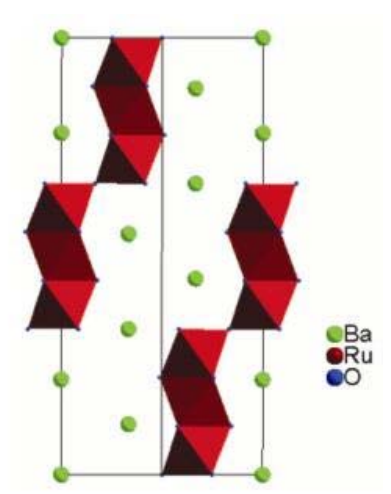

(c)

Figure 11. Crystal structures of (a) $\mathrm{BaBiO}_{3}$, (b) $\mathrm{Ba}_{1-x} \mathrm{~K}_{x} \mathrm{BiO}_{3}(x \sim 0 \cdot 4)$ and (c) $9 \mathrm{R} \mathrm{BaRuO}_{3}$ perovskite related oxides.

with a minimal change in the coordination spheres of the redox centres, as for example, in the $\mathrm{Fe}^{\mathrm{II}}\left(\mathrm{H}_{2} \mathrm{O}\right)_{6} /$ $\mathrm{Fe}^{\mathrm{III}}\left(\mathrm{H}_{2} \mathrm{O}\right)_{6}$ reaction.

In discussing the application of these ideas to solid state chemistry, it is useful to make a distinction between mixed valent systems where the valences differ by one or two units. Typical examples of the mixed valence systems where there is a difference of single valence are the superconducting $\mathrm{La}_{2-x} \mathrm{Sr}_{x} \mathrm{CuO}_{4}\left(\mathrm{Cu}^{\mathrm{II}}, \mathrm{Cu}^{\mathrm{III}}\right)$, metallic $\mathrm{Na}_{\mathrm{x}} \mathrm{WO}_{3}\left(\mathrm{~W}^{\mathrm{V}}\right.$, $\left.\mathrm{W}^{\mathrm{VI}}\right)$ and the magnetoresistive $\mathrm{La}_{1-x} \mathrm{Ca}_{x} \mathrm{MnO}_{3}\left(\mathrm{Mn}^{\mathrm{III}}\right.$, $\mathrm{Mn}^{\mathrm{IV}}$ ). In all these cases, a nominally single valent parent oxide, $\mathrm{La}_{2} \mathrm{CuO}_{4}, \mathrm{WO}_{3}$ and $\mathrm{LaMnO}_{3}$, is doped appropriately to create the mixed valent state. ${ }^{67,68}$ Materials of this kind could belong to either Class II or Class III. Superconducting $\mathrm{La}_{2-x} \mathrm{Sr}_{x} \mathrm{CuO}_{4}$ and ferromagnetic and metallic $\mathrm{La}_{1-x} \mathrm{Ca}_{x} \mathrm{MnO}_{3}$ for $x \leq 0 \cdot 3$ are Class III type where the electrons are delocalized, whereas the charge ordered $\mathrm{Ln}_{0.5} \mathrm{Ca}_{0.5} \mathrm{MnO}_{3}$ $\left(\mathrm{Ln}=\right.$ rare earth), where $\mathrm{Mn}^{\mathrm{III}}$ and $\mathrm{Mn}^{\mathrm{IV}}$ are ordered on distinct crystallographic sites (and the electrons are localized) are Class II. $\mathrm{Fe}_{3} \mathrm{O}_{4}$ (magnetite), which is ferrimagnetic and nearly metallic above $123 \mathrm{~K}$ is a well known example of a mixed valence system, where the octahedral site $\mathrm{Fe}^{\mathrm{II}}$ and $\mathrm{Fe}^{\mathrm{III}}$ order at low temperatures (below $120 \mathrm{~K}$ ). The related warwickite compound, $\mathrm{Fe}^{\mathrm{II}} \mathrm{Fe}^{\mathrm{III}} \mathrm{OBO}_{3}$, also exhibits a charge ordered state below $317 \mathrm{~K}$, albeit the material is paramagnetic and insulating. ${ }^{69}$

Ordered double perovskites of the kind $\mathrm{A}_{2} \mathrm{FeReO}_{6}$ $(\mathrm{A}=\mathrm{Ca}, \mathrm{Sr}, \mathrm{Ba})$ (figure 4) exhibit mixed valence of a different kind ${ }^{39}$ that causes the half metallic and ferrimagnetic character. The barium and strontium compounds of the rhenium series show a mixed valency of $\mathrm{Fe}^{\mathrm{II}} / \mathrm{Fe}^{\mathrm{III}}$ and $\mathrm{Re}^{\mathrm{V}} / \mathrm{Re}^{\mathrm{VI}}$, whereas in the calcium compound, the valencies seem to have been frozen at $\mathrm{Fe}^{\mathrm{III}}$ and $\mathrm{Re}^{\mathrm{V}}$. Analogous members of this series $\mathrm{Ba}_{2} \mathrm{MReO}_{6}(\mathrm{M}=\mathrm{Mn}, \mathrm{Ni})$ are ferromagnetic but not metallic. ${ }^{39 b}$ The results clearly reveal that mixed valency is crucial to the metallic property whereas both fixed/mixed valency could give rise to ferrimagnetism.

Mixed valent systems where there is a difference of two valence states between the metal centres are unusual in several respects. ${ }^{67} \mathrm{BaBiO}_{3}$, which could be regarded as having formed by disproportionation of formal $\mathrm{Bi}^{\mathrm{IV}}\left(6 s^{1}\right)$ to $\mathrm{Bi}^{\mathrm{III}}\left(6 s^{2}\right)$ and $\mathrm{Bi}^{\mathrm{V}}\left(6 s^{0}\right)$, is a typical example of this kind. ${ }^{70}$ Electron transfers associated with $\mathrm{BaBiO}_{3} \equiv \mathrm{Ba}_{2} \mathrm{Bi}^{\mathrm{III}} \mathrm{Bi}^{\mathrm{V}} \mathrm{O}_{6}$, and $\mathrm{CsAuCl}_{3} \equiv$ $\mathrm{Cs}_{2}\left(\mathrm{Au}^{\mathrm{I}} \mathrm{Cl}_{2}\right)\left(\mathrm{Au}^{\mathrm{III}} \mathrm{Cl}_{4}\right)$ could be regarded as having occurred by the inner sphere mechanism (because there is a clear change in the coordination sphere and a shift of the anions as compared to the hypothetical parent analogs); on the other hand, Class III mixed valency as in metallic and ferromagnetic $\mathrm{La}_{1-x} \mathrm{Ca}_{x} \mathrm{MnO}_{3}$ and superconducting $\mathrm{La}_{2-x} \mathrm{Sr}_{x} \mathrm{CuO}_{4}$ and $\mathrm{YBa}_{2} \mathrm{Cu}_{3} \mathrm{O}_{7}$ (figure 12) could be regarded as occurring by an outer sphere mechanism.

Let us consider the mixed valency of two wellknown oxide superconductors, ${ }^{70,71} \mathrm{La}_{2-x} \mathrm{Sr}_{x} \mathrm{CuO}_{4}$ and $\mathrm{Ba}_{1-x} \mathrm{~K}_{x} \mathrm{BiO}_{3}$, in an effort to probe the role of mixed valency in superconductivity. Both the superconductors are obtained from the nonsuperconducting parent oxides, $\mathrm{La}_{2} \mathrm{CuO}_{4}$ and $\mathrm{BaBiO}_{3}$, respectively, by hole doping. The electronic structures of the parent oxides however are quite different: $\mathrm{La}_{2} \mathrm{CuO}_{4}$ is an antiferromagnetic Mott (charge-transfer) insulator, where the divalent $\mathrm{Cu}^{\mathrm{II}}\left(t_{2 g}{ }^{6} e_{g}{ }^{3}\right)$ occurs in a $J-T$ distorted (axially elongated) octahedral coordination that leaves the unpaired electron in the $d_{x^{2}-y^{2}}$ orbital. The unpaired electrons are essentially localized on copper but strongly coupled through nearly linear 

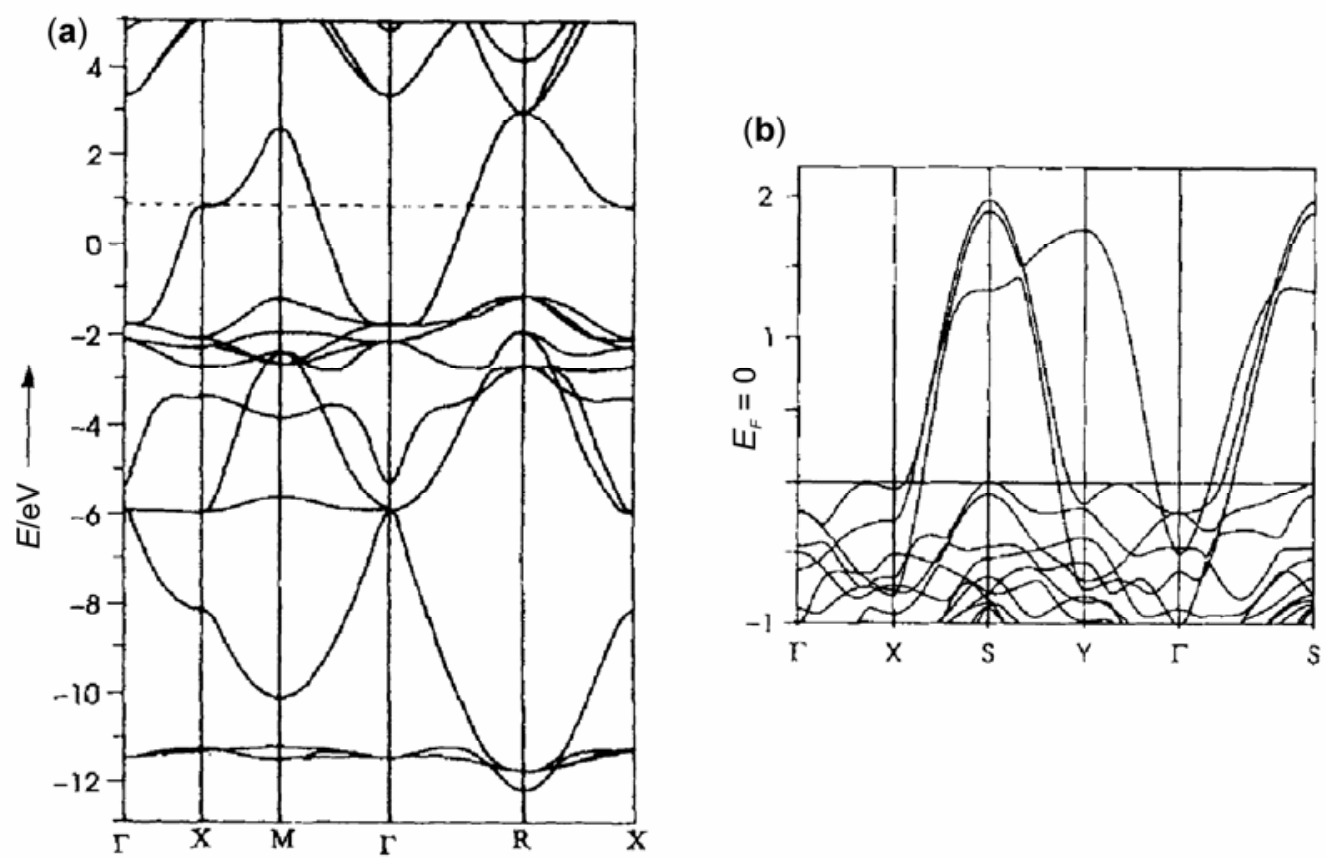

Figure 12. Band structures of (a) $\mathrm{Ba}_{0.5} \mathrm{~K}_{0.5} \mathrm{BiO}_{3}$ and (b) $\mathrm{YBa}_{2} \mathrm{Cu}_{3} \mathrm{O}_{7}$ showing 'flat' and 'steep' bands at $E_{F}$ (from ref. 72).

$\mathrm{Cu}-\mathrm{O}-\mathrm{Cu}$ linkages giving rise to antiferromagnetism. It is essentially the Mott-Hubbard energy U that causes the localization and prevents the material from becoming an electronic conductor (state I).

$$
\begin{array}{ccc}
\mathrm{Cu}^{\mathrm{II}} \mathrm{Cu}^{\mathrm{II}} & \rightarrow\left(\mathrm{Cu}^{\mathrm{III}} \mathrm{Cu}^{\mathrm{I}} \leftrightarrow \mathrm{Cu}^{\mathrm{I}} \mathrm{Cu}^{\mathrm{III}}\right) & \rightarrow \mathrm{Cu}^{\mathrm{III}} \mathrm{Cu}^{\mathrm{I}} \\
+U & U=0 & -U \\
\mathrm{I} & \mathrm{II} & \text { III }
\end{array}
$$

In the atomic limit (band effects are ignored), $U$ corresponds to $I-A$, where $\mathrm{I}$ is the ionization energy, $\mathrm{Cu}^{\mathrm{II}} \rightarrow \mathrm{Cu}^{\mathrm{III}}+\mathrm{e}^{-}$, and $A$ is the electron affinity. When $U=0$, electron transfer between adjacent $\mathrm{Cu}^{\mathrm{II}}$ would occur and the material would become a conductor (state II). Another possible electronic state for $\mathrm{La}_{2} \mathrm{CuO}_{4}$ is depicted in III, where the valence states $\mathrm{Cu}^{\mathrm{I}}$ and $\mathrm{Cu}^{\mathrm{III}}$ are frozen and the electrons are localized. This state corresponds to the so-called charge-disproportionated state where the mixed valency of copper differs by two units. As compared to the conducting state II, the valence disproportionated state III is stabilized by an energy $-U$ (negative Hubbard energy). For $\mathrm{La}_{2} \mathrm{CuO}_{4}$ under normal conditions, states II and III are however hypothetical. For $\mathrm{BaBiO}_{3}$, the ground state corresponds to state III, where $\mathrm{Bi}^{\mathrm{IV}}$ has disproportionated into $\mathrm{Bi}^{\mathrm{III}} \mathrm{Bi}^{\mathrm{V}}$ under ambient conditions. States I and II are hypothetical for $\mathrm{BaBiO}_{3}$.

$$
\begin{array}{ccc}
\mathrm{Bi}^{\mathrm{IV}} \mathrm{Bi}^{\mathrm{IV}} \rightarrow\left(\mathrm{Bi}^{\mathrm{III}} \mathrm{Bi}^{\mathrm{V}} \leftrightarrow \mathrm{Bi}^{\mathrm{V}} \mathrm{Bi}^{\mathrm{III}}\right) \rightarrow \mathrm{Bi}^{\mathrm{III}} \mathrm{Bi}^{\mathrm{V}} \\
+U & U=0 & -\mathrm{U} \\
\mathrm{I} & \mathrm{II} & \text { III }
\end{array}
$$

Now, let us turn to hole doping of $\mathrm{La}_{2} \mathrm{CuO}_{4}$ and $\mathrm{BaBiO}_{3}$. Hole doping renders copper mixed valent, $\mathrm{Cu}^{\mathrm{II}} \mathrm{Cu}^{\mathrm{III}}$, as in $\mathrm{La}_{2-x} \mathrm{Sr}_{x} \mathrm{CuO}_{4}$ for example, and at a critical concentration of holes $(x)$, the material becomes metallic (the Hubbard $U$ vanishes) and also superconducting. Hole doping of $\mathrm{BaBiO}_{3} \equiv \mathrm{Ba}_{2} \mathrm{Bi}^{\mathrm{III}}$ $\mathrm{Bi}^{\mathrm{V}} \mathrm{O}_{6}$ results in oxidation of bismuth, increasing the proportion of $\mathrm{Bi}^{\mathrm{V}}$ to $\mathrm{Bi}^{\mathrm{III}}$, and at a critical concentration of holes $(x)$ as in $\mathrm{Ba}_{1-x} \mathrm{~K}_{x} \mathrm{BiO}_{3}$, the material becomes conducting and also superconducting. The distorted perovskite structure of the parent $\mathrm{Ba}_{2} \mathrm{Bi}^{\mathrm{III}}$ $\mathrm{Bi}^{\mathrm{V}} \mathrm{O}_{6}$ (where there are two distinct sites for bismuth) becomes undistorted/cubic perovskite in $\mathrm{Ba}_{1-x}$ $\mathrm{K}_{x} \mathrm{BiO}_{3}$ where there is only one bismuth site and only one $\mathrm{BiO}_{6}$ octahedron (figure 11). Clearly, hole doping drives the material from the insulating state (III) to conducting state (II), and the $-U$ at the bismuth site vanishes. In both the superconductors, copper and bismuth are mixed valent, $\mathrm{Cu}^{\mathrm{II}} / \mathrm{Cu}^{\mathrm{III}}$ and $\mathrm{Bi}^{\mathrm{IV}} / \mathrm{Bi}^{\mathrm{V}}$ or $\mathrm{Bi}^{\mathrm{III}} / \mathrm{Bi}^{\mathrm{IV}} / \mathrm{Bi}^{\mathrm{V}}$, but with only one site for the mixed valent metal and the electron transfer occurring at a time scale faster than the vibrational time scale. Accordingly, they would be classified as 
Class III mixed valent systems in the Robin-Day scheme.

In this picture, the mixed valency of the two superconductors are not any different from the mixed valency of other similar systems say for example $\mathrm{La}_{2-x} \mathrm{Sr}_{x} \mathrm{NiO}_{4}$ and $\mathrm{La}_{1-x} \mathrm{Ca}_{x} \mathrm{MnO}_{3}(x<0 \cdot 5)$ which are not superconducting. Therefore, the question arises as to what is special about the cuprate and the bismuthate that makes them go superconducting. There is no definite answer for this question as yet and it remains a conspicuous unsolved problem of condensed matter theory today.

From the chemistry point of view, there are however some useful insights especially from the works of Arndt Simon ${ }^{72}$ into what probably might be happening with the superconducting materials. A critical examination of the electronic structures of a large number of superconductors including the high $T_{C}$ cuprates and other novel systems such as the rare earth carbide halides $\left(\mathrm{RE}_{2} \mathrm{C}_{2} \mathrm{X}_{2}\right), \mathrm{MgB}_{2}$, elemental tin and mercury by Simon and co-workers has revealed a special signature of the superconducting materials, which provides an insight into the chemical bonding and possibly to the mechanism of superconductivity in general. The occurrence of flat/ steep bands at $E_{F}$ in the electronic structure of the normal state of the superconductor is a crucial factor in Simon's model (figure 12). The flat band is a section of a band at $E_{F}$ where the group velocities of the charge carriers approach zero. The steep band is defined as a section of the band crossing the Fermi level where the charge carriers possess a high velocity. Flat bands signify localization of conduction electrons, whereas steep bands denote delocalized electrons. The flat/steep band model is also consistent with a number of experimental observations ${ }^{73,74}$ of high $T_{C}$ cuprates, such as formation of quantum stripes and an overall dynamic charge inhomogenity, reflecting electron-phonon coupling (revealed by inelastic neutron scattering), existence of two gaps (revealed by muon spin rotation, a large one with $d$ wave and a small one with s-wave symmetry) and softening of a half breathing mode but not the full breathing mode; all of them point to the special electronic structure of the high $T_{C}$ cuprates and the bismuthate, where the tendency towards localization of a part of the conduction electrons is seen in the normal state. In chemical terms, the existence of both flat/steep bands and the inhomogeneous nature of charge carriers in superconductors point to a 'pairwise localization of conduction electrons' as the ori- gin for superconductivity. The "pair-wise localization' would correspond to different chemical entities in different cases: thus in the bismuthate and cuprates, this would be valence disproportionation, $\mathrm{Cu}^{\mathrm{II}} \rightarrow \mathrm{Cu}^{\mathrm{I}}+\mathrm{Cu}^{\mathrm{III}}$ and $\mathrm{Bi}^{\mathrm{IV}} \rightarrow \mathrm{Bi}^{\mathrm{III}}+\mathrm{Bi}^{\mathrm{V}}$, and consequent formation of 'lone/inert pairs' which actually become the Cooper pairs in the superconducting state. In $\mathrm{RE}_{2} \mathrm{C}_{2} \mathrm{X}_{2}$, the pair-wise localization causing superconductivity corresponds to formation of a chemical bond involving the $\mathrm{C}_{2}-\pi^{*}$ states. ${ }^{72}$ The problem with the flat/steep band model, as pointed out by Simon himself, is: it is a necessary but not sufficient criterion for the occurrence of superconductivity and secondly, the flat bands are such tiny features in the band structure that their identification, even if responsible for superconductivity, resembles rather the search for a needle in a haystack! $!^{75}$

We believe that it is exactly here that chemical intuition would come to help in the research/identification of new superconducting systems. If we agree that mixed valency of the valence disproportionation type, $\mathrm{Bi}^{\mathrm{IV}} \rightarrow \mathrm{Bi}^{\mathrm{iII}}+\mathrm{Bi}^{\mathrm{V}}$ or $\mathrm{Cu}^{\mathrm{II}} \rightarrow \mathrm{Cu}^{\mathrm{I}}+$ $\mathrm{Cu}^{\text {III }}$, that is essential for the occurrence of superconductivity in $\mathrm{Ba}_{1-x} \mathrm{~K}_{x} \mathrm{BiO}_{3}$ and $\mathrm{La}_{2-x} \mathrm{Sr}_{x} \mathrm{CuO}_{4}$ (as was pointed out by Sleight), ${ }^{70}$ one could speculate the following for the new superconductors. $\mathrm{Cs}_{2} \mathrm{Au}^{\mathrm{I}} \mathrm{Au}^{\mathrm{III}} \mathrm{X}_{6}(\mathrm{X}=\mathrm{Cl}, \mathrm{Br})$ is a classical mixed valent compound that is similar to $\mathrm{Ba}_{2} \mathrm{Bi}^{\mathrm{III}} \mathrm{Bi}^{\mathrm{V}} \mathrm{O}_{6}$. At high pressures, $\mathrm{Cs}_{2} \mathrm{Au}_{2} \mathrm{X}_{6}$ transforms into a single valence $\mathrm{Au}^{\mathrm{II}}$ state, that is conducting but not superconducting. ${ }^{76}$ If a charge imbalance could be created in the conducting state by appropriately doping with holes, an electronic situation analogous to that in $\mathrm{Ba}_{1-x} \mathrm{~K}_{x} \mathrm{BiO}_{3}$ would be created with the possible occurrence of superconductivity. $\mathrm{LaNiO}_{3}$ and other $\mathrm{LnNiO}_{3}(\mathrm{Ln}=$ rare earth, $\mathrm{Y})$ are perovskite oxides where a superconducting state could perhaps be realized by appropriate doping and change of chemistry. While $\mathrm{LaNiO}_{3}$ is a metallic perovskite under ordinary conditions consisting of single valent $\mathrm{Ni}^{\mathrm{III}}$ (low spin $d^{7}: t_{2 g}{ }^{6} e_{g}{ }^{1}$ ), members of this family containing heavy rare earth and yttrium prepared under high oxygen pressure, show a charge separated insulating state $^{77}$ where the nickel has undergone a disproportionation, $2 \mathrm{Ni}^{\mathrm{III}} \rightarrow \mathrm{Ni}^{\mathrm{III}+\delta}+\mathrm{Ni}^{\mathrm{III}-\delta}$. If these materials could be appropriately doped with holes, as for example, in $\mathrm{La}_{1-x} \mathrm{Sr}_{x} \mathrm{NiO}_{3}$ and $\mathrm{Ln}_{1-x} \mathrm{Sr}_{x} \mathrm{NiO}_{3}$, a superconducting state could perhaps be realized. Similarly, in analogy with $\mathrm{BaPb}_{1-x} \mathrm{Bi}_{x} \mathrm{O}_{3}(x \sim 0.25)$ superconductor, ${ }^{78}$ where a nonsuperconducting (but metallic) 
$\mathrm{BaPbO}_{3}$ is rendered superconducting by the substitution $\mathrm{Pb}^{\mathrm{IV}}\left(s^{0}\right) / \mathrm{Bi}^{\mathrm{IV}}\left(s^{1}\right)$, a similar electronic situation would be created in $\mathrm{LaCo}_{1-x} \mathrm{Ni}_{x} \mathrm{O}_{3}$, where, for values of $x<0.5$, superconductivity could possibly be realized. One must however remember that superconductivity especially that of metal oxides is a complex topic involving several factors and therefore no simplistic predictions can be made. Mixed valency may be one of the criteria; there could be other criteria such as that proposed by Krebs: ${ }^{79}$ a partially occupied band should be formed in such a way that the electrons can move at least in one direction without encountering 'nodes'.

Undoubtedly, discovery of new superconductors is a daunting task that is exercising the best of minds at present. We believe that a chemistry-based approach that takes into account the complex interplay of crystal and electronic structures, keeping an eye for mixed valency and pair-wise localization of charges in chemical bonds/lone pairs in a Fermi sea of electrons, would likely be fruitful for this endeavor.

In this context, the recent discovery of superconductivity in two new classes of $\mathrm{Fe}$-based materials, $\mathrm{LaO}_{1-x} \mathrm{~F}_{x} \mathrm{FeAs} \quad\left(T_{C}=43 \mathrm{~K}\right)^{79 \mathrm{~b}}$ and $\mathrm{Ba}_{1-x} \mathrm{~K}_{x} \mathrm{Fe}_{2} \mathrm{As}_{2}$ $\left(T_{C}=38 \mathrm{~K}\right)^{79 \mathrm{c}}$ is noteworthy. Interestingly, both these classes of materials adopt layered structures containing $\mathrm{FeAs}$ layers separated by $\mathrm{LaO}$ or $\mathrm{Ba} / \mathrm{K}$ layers, where evolution of superconductivity by carrier doping in a layered structure creating mixed valent $\mathrm{Fe} / \mathrm{As}$ suggest a similarity to the cuprate superconductors. ${ }^{79 \mathrm{~d}}$

\subsection{Metal-metal bonding}

Metal-metal bonding is a topic of great interest for both molecular inorganic chemistry and solid state chemistry. In the molecular context, we are familiar with essentially two kinds of metal-metal bonds: bonds that connect two metal atoms and bonds that connect a cluster of (three or more) metal atoms. Well-known examples of the first kind are $\mathrm{Re}_{2} \mathrm{Cl}_{8}^{2-}$, $\mathrm{Mn}_{2}(\mathrm{CO})_{10}, \mathrm{Mo}_{2}\left(\mathrm{CH}_{3} \mathrm{COO}\right)_{4}$ and $\mathrm{Hg}_{2} \mathrm{X}_{2}(\mathrm{X}=$ halide $)$. Among the transition metals, metal-metal bonding is common for metals in low oxidation states and generally the tendency/strength varies as $3 d<<4 d$ $<5 d$. Typical examples of metal-metal bonded clusters containing more than two metal atoms are $\mathrm{M}_{6} \mathrm{X}_{12}$ and $\mathrm{M}_{6} \mathrm{X}_{8}$ units (figure 13), which occur either discrete or in condensed form in several low valence compounds of $4 d, 5 d$ and even $4 f$ metals (figure 13). Both the units consist of an $\mathrm{M}_{6}$ octahedron where the metals are connected by $\mathrm{M}-\mathrm{M}$ bonds and bridged by the $\mathrm{X}$ anions; in $\mathrm{M}_{6} \mathrm{X}_{12}$, the anions are at the edges, while in $M_{6} X_{8}$, they occur at the faces of the octahedron. Discrete $\mathrm{M}_{6} \mathrm{X}_{12}$ clusters are found in $\mathrm{Zr}_{6} \mathrm{I}_{12}, \mathrm{Nb}_{6} \mathrm{~F}_{15}, \mathrm{Ta}_{6} \mathrm{Cl}_{15}$, as well as, in $\mathrm{FeZr}_{6} \mathrm{I}_{14} \cdot \mathrm{Nb}_{6} \mathrm{I}_{11}$ is a typical example of a solid that contains discrete $\mathrm{M}_{6} \mathrm{X}_{8}$ clusters; the compound is formulated as $\left[\mathrm{Nb}_{6} \mathrm{I}_{8}\right] \mathrm{I}_{6 / 2}$ to indicate the presence of two different kinds of iodides. Both $\mathrm{M}_{6} \mathrm{X}_{8}$ and $\mathrm{M}_{6} \mathrm{X}_{12}$ clusters form the basis for the structural chemistry of a large number of lower valence transition metal halides, chalcogenides, pnictides, carbides, silicides and so on. While the synthetic chemistry of this class of compounds has been explored by John Corbett ${ }^{80}$ uncovering endless wonders in this field, the structural principles underlying the complex architecture of these solids and their relationship to the electronic structure have been unravelled largely by Arndt Simon. ${ }^{81}$

A series of solids containing $\mathrm{M}_{6} \mathrm{X}_{8}$ clusters that attracted the attention of solid state chemists some time back are the Chevrel phases, ${ }^{82} \mathrm{M}_{x} \mathrm{Mo}_{6} \mathrm{X}_{8}(\mathrm{X}=$ $\mathrm{S}, \mathrm{Se}$ ) (figure 13), because of their superconducting properties. Synthesis of stoichiometric and singlephase samples, avoiding competitive/impurity phases by easily accessible methods, is a challenging task in solid state chemistry, particularly so for the Chevrel phases and other chalcogenides. Towards this end, we adopted two strategies: in the first, we have taken recourse to the precursor route (which we developed and employed successfully for the synthesis of oxide materials) ${ }^{83}$ For this purpose, we prepared chemical precursors ${ }^{84}$ of the general formula, $\mathrm{M}_{p}\left(\mathrm{NH}_{4}\right)_{9} \mathrm{Mo}_{3} \mathrm{~S}_{9}(\mathrm{M}=\mathrm{Cu}, \mathrm{Pb}, \mathrm{La}$ or $\mathrm{Gd})$ by the reaction of ammonium thiomolybdate with appropriate metal (M) chlorides in DMF. Decomposition of the precursors in hydrogen atmosphere around $1000^{\circ} \mathrm{C}$ yielded Chevrel phase sulfides exhibiting superconductivity and other relevant properties. In our second strategy, ${ }^{85}$ we investigated Pt (1 atom \%) - catalysed hydrogen-reduction of $\mathrm{MoS}_{2}$ and $\mathrm{WS}_{2}$ (together with the ternary metal) at elevated temperatures. We could prepare by this route several lower valence molybdenum and tungsten sulfides, $\mathrm{Mo}_{2} \mathrm{~S}_{3}, \mathrm{Mo}_{6} \mathrm{~S}_{8}, \mathrm{M}_{21} \mathrm{~S}_{8}, \mathrm{M}_{14} \mathrm{~S}_{5}(\mathrm{M}=\mathrm{Mo}, \mathrm{W})$ as well as the Chevrel phases. The structures of these solids are likely derived by a condensation of $\mathrm{M}_{6} \mathrm{~S}_{8}$ clusters through vertices to give $\mathrm{M}_{5} \mathrm{~S}_{4}$ onedimensional columns which further condense through linking the edges. ${ }^{81}$ 


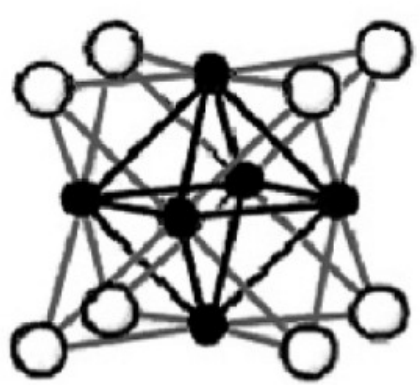

(a)

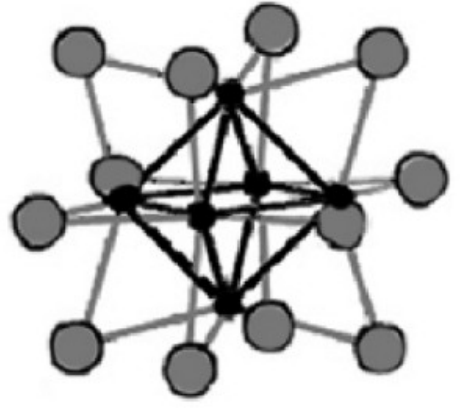

(b)

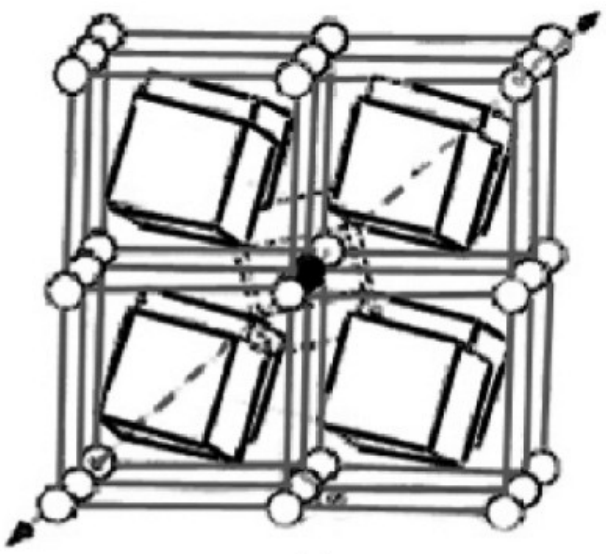

(c)

Figure 13. Metal-metal bonded clusters in (a) $\mathrm{M}_{6} \mathrm{X}_{8}$, (b) $\mathrm{M}_{6} \mathrm{X}_{12}$ and (c) Chevrel phases.

Metal-metal bonding in metal oxides consisting of metal-oxygen octahedra is equally fascinating and fundamental to their special structures and properties. The structures of $\mathrm{TiO}, \mathrm{VO}$ and $\mathrm{NbO}$ are traditionally described as defect rocksalt type containing vacancies at both cation and anion sublattices. Another, perhaps more realistic, description of the structure of $\mathrm{NbO}$ would be to consider it as having formed by a condensation of $\mathrm{Nb}_{6} \mathrm{O}_{12}$ units to give $\mathrm{Nb}_{6 / 2} \mathrm{O}_{12 / 4} \equiv \mathrm{Nb}_{3} \mathrm{O}_{3} \equiv \mathrm{NbO}$ (figure 14). $\mathrm{NaMo}_{4} \mathrm{O}_{6}$ is a unique metal-metal bonded oxide material, prepared by Torardi and McCarley, ${ }^{86}$ that is derived from $\mathrm{Mo}_{6} \mathrm{O}_{12}$ clusters which are trans-edge linked to give interconnecting chains that accommodate the sodium atoms (figure 14).

Metallic and magnetic/superconducting properties of rocksalt based oxides, $\mathrm{TiO}, \mathrm{VO}$ and $\mathrm{NbO}$, arise from a strong metal-metal bonding across the facediagonals of the rocksalt structure, where the $\mathrm{M}-\mathrm{M}$ distances are in the range $(\sim 2.9 \AA)$ that is favourable for a direct metal-metal interaction through the $t_{2 g}$ set of $d$ orbitals, as pointed out first by Goodenough. ${ }^{87}$ Metal-metal bonding is important for understanding the structure and properties of several other families of transition metal oxides belonging for instance to the corundum, rutile and perovskite structure types. The rutile-based oxides, $\mathrm{TiO}_{2}, \mathrm{VO}_{2}$, $\mathrm{CrO}_{2}$ and $\mathrm{MoO}_{2}$, are particularly noteworthy. ${ }^{88}$ The rutile structure (figure 15) is specially suited for the formation of metal-metal bonds along the tetragonal $c$-axis, where the $\mathrm{MO}_{6}$ octahedra share opposite edges, forming chains of metal atoms. While rutile $\left(\mathrm{TiO}_{2}\right)$ itself does not form metal-metal bonds $\left[\mathrm{Ti}^{4+}\right.$ $\left(3 d^{0}\right)$ ], the next member $\mathrm{VO}_{2}$ crystallizes in a characteristic monoclinic distorted rutile structure (fig- ure 15), wherein $\mathrm{V}^{4+}\left(3 d^{1}\right)$ electrons are involved in metal-metal $(\mathrm{V}-\mathrm{V})$ bonds, rendering the material an electronic insulator. We see alternating short $(2.65 \AA)$ and long $(3 \cdot 12 \AA) \mathrm{V}-\mathrm{V}$ distances in the monoclinic structure, the short distance corresponding to the formation of a single $\mathrm{V}-\mathrm{V}$ bond. At $340 \mathrm{~K}, \mathrm{VO}_{2}$ shows a sharp insulator-metal transition that is accompanied by a structural transition where the monoclinic structure gives way to the undistorted tetragonal rutile structure. Clearly the $\mathrm{V}-\mathrm{V}$ bond is broken at the transition $(\mathrm{V}-\mathrm{V}$ distances are uniform, $2.88 \AA$ ) and the $3 d$ electrons are released from metal-metal bonding to make the tetragonal rutile $\mathrm{VO}_{2}$ a metallic conductor. $\mathrm{MoO}_{2}\left[\mathrm{Mo}^{4+}\left(4 d^{2}\right)\right]$ and its $5 d$ analogue $\mathrm{WO}_{2}$ are isostructural with monoclinic $\mathrm{VO}_{2}$, but a transition to the tetragonal rutile structure has not been reported. We have recently found evidence ${ }^{89}$ for such a transition in thermodynamic measurements of the Gibbs free energy and entropy of formation of $\mathrm{MoO}_{2}$ over a wide temperature range (925-1925 K) using solid state e.m.f. measurements. A transition presumably to the rutile phase occurs at $1533 \mathrm{~K}$. The high temperature of the transition clearly reflects a stronger metalmetal bonding in $\mathrm{MoO}_{2}$ than in $\mathrm{VO}_{2}$. It would be interesting to investigate the related $\mathrm{WO}_{2}$ (and other monoclinic rutile based $\mathrm{MO}_{2}$ oxides) to find out whether they exhibit a similar transition and also the electronic properties of the rutile phase materials. Considering that the monoclinic structure of $\mathrm{MoO}_{2}$ and $\mathrm{WO}_{2}$ consists of pair-wise localization of part of the $\mathrm{d}$ electrons in $\mathrm{M}-\mathrm{M}$ bonds while retaining their metallic character, a hole doping of these materials by appropriate chemistry would be interesting in the search of new superconductors. 


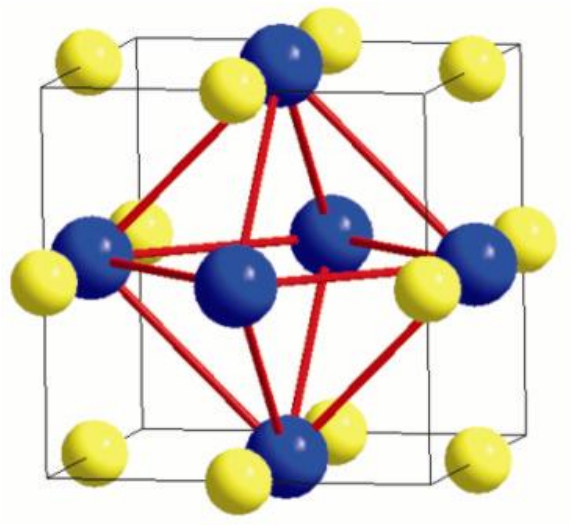

(a)

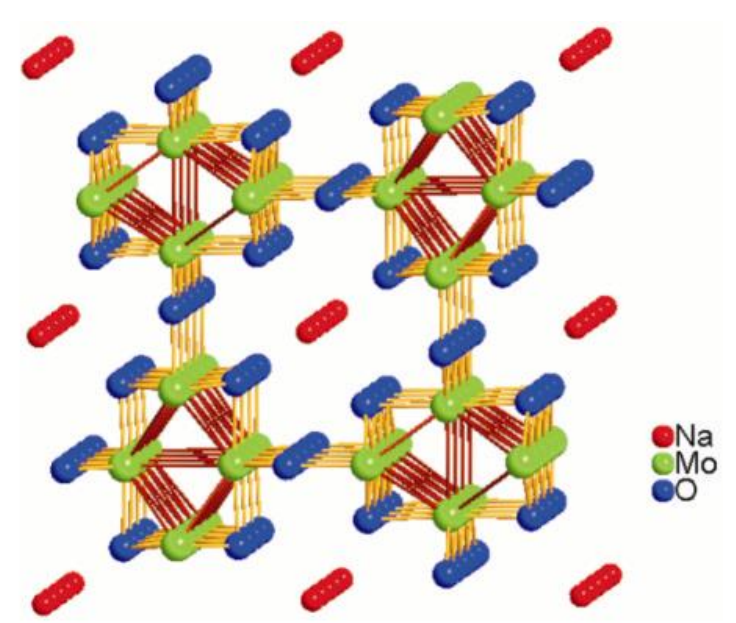

(b)

Figure 14. Crystal structures of (a) $\mathrm{NbO}$ and (b) $\mathrm{NaMo}_{4} \mathrm{O}_{6}$.

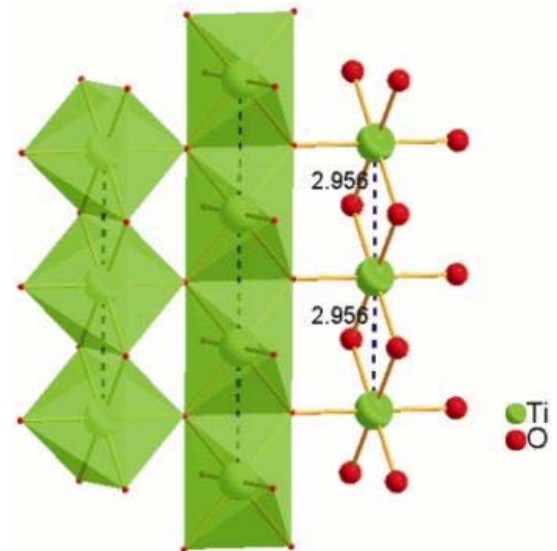

(a)

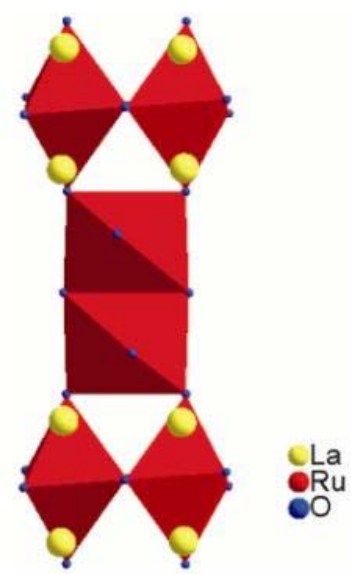

(c)

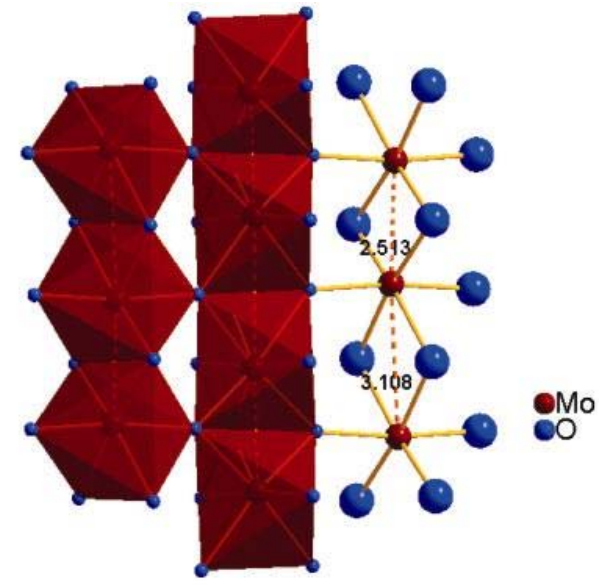

(b)

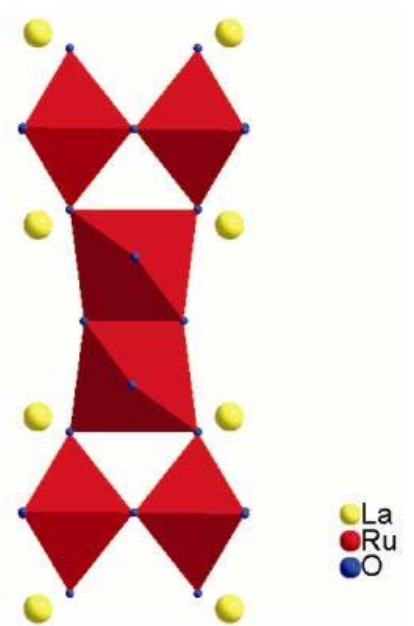

(d)

Figure 15. Crystal structures of (a) rutile, (b) distorted rutile, $\mathrm{VO}_{2}$ and $\mathrm{MoO}_{2}$, (c) $\mathrm{La}_{4} \mathrm{Ru}_{6} \mathrm{O}_{19}$ and (d) $\mathrm{La}_{3} \mathrm{Ru}_{3} \mathrm{O}_{11}$. 
Although a metal-metal bonding in the conventional $\mathrm{AMO}_{3}$ perovskite (3C) structure (figure 11) does not occur [because of the long $(\sim 5.5 \AA) \mathrm{M}-\mathrm{M}$ distance across the face-diagonal of the cubic structure], metal-metal bonding in hexagonal perovskite polytypes is well-known. For example, $\mathrm{BaRuO}_{3}$ which adopts the 9R polytypic structure (figure 11) where $\mathrm{RuO}_{6}$ octahedra are face-shared to give $\mathrm{Ru}_{3} \mathrm{O}_{12}$ trioctahedral clusters, which are further connected through corners. ${ }^{90}$ Direct $\mathrm{Ru}-\mathrm{Ru}$ bonding across the face-shared octahedra occurs in this material (which is quite similar to the metal-metal bonding found in the trioctahedral molecular anion, $\mathrm{Ru}_{3} \mathrm{Cl}_{12}^{4}$ ) giving rise to the observed electrical and magnetic properties: $9 \mathrm{R} \mathrm{BaRuO}_{3}$ is metallic but passes over to a more resistive state ${ }^{91}$ below $100 \mathrm{~K}$ and there is no local magnetic moment on ruthenium below $400 \mathrm{~K}$. On the other hand, an isostructural material $\mathrm{Ba}_{3} \mathrm{Ru}_{2} \mathrm{MnO}_{9}$ prepared by us ${ }^{92}$ also contains $\mathrm{Ru}_{2} \mathrm{MnO}_{12}$ cluster and shows an $S=1 / 2$ magnetic behaviour that could be rationalized only on the basis of a strong metal-metal bonding between $\mathrm{Mn} / \mathrm{Ru}$ atoms in the trioctahedral clusters.

$\mathrm{La}_{4} \mathrm{Ru}_{6} \mathrm{O}_{19}$ and $\mathrm{La}_{3} \mathrm{Ru}_{3} \mathrm{O}_{11}$ are novel metal oxides ${ }^{93}$ that contain edge-shared octahedral $\mathrm{Ru}_{2} \mathrm{O}_{10}$ dimers where metal-metal bonding plays a crucial role on the electronic properties. Although the rutheniumoxygen framework is similar (figure 15) and the ruthenium oxidation state the same $(+4.33)$ in both the oxides, a direct $\mathrm{Ru}-\mathrm{Ru}$ bonding $(2.490 \AA)$ occurs in $\mathrm{La}_{4} \mathrm{Ru}_{6} \mathrm{O}_{19}$, whereas no such bonding occurs in $\mathrm{La}_{3} \mathrm{Ru}_{3} \mathrm{O}_{11}(\mathrm{Ru}-\mathrm{Ru}$ distance 2.944 $\AA$ ). Presence of distinct metal-metal bonded dimers in $\mathrm{La}_{4} \mathrm{Ru}_{6} \mathrm{O}_{19}$ resulting in both localized and delocalized electrons confers a unique non-Fermi liquid behaviour to this material, whereas $\mathrm{La}_{3} \mathrm{Ru}_{3} \mathrm{O}_{11}$ shows a normal Fermi liquid behaviour. We have investigated the substitution of manganese for ruthenium in the pyrochlore $\mathrm{Bi}_{2} \mathrm{Ru}_{2} \mathrm{O}_{7}$ that reveals novel electronic interactions between $\mathrm{Ru}(4 d)$ and $\mathrm{Mn}(3 d)$ atoms in this framework. ${ }^{94}$

\section{Concluding remarks}

In this article, we have tried to illustrate the role of chemistry - especially inorganic chemistry - in the practice of current materials chemistry research. The utility/application of the well-known concepts of inorganic chemistry-acidity/basicity, redox reactions, crystal field theory, Jahn-Teller distortions, mixed valence and electron transfer, and last but not the least, metal-metal bonding - for the design, synthesis, structure and properties of several extended inorganic solid materials has been illustrated, drawing examples from the research work of the senior author as well as from the current literature. We have paid special attention to metal oxide systems which continue to dominate current materials chemistry and where all the foregoing inorganic chemistry concepts find exemplary application. We have also discussed at some length the relevance of mixed valence chemistry for superconducting oxides. It must be pointed out in closing that there are several other aspects of inorganic chemistry such as ionicity/covalency, metal-ligand charge transfer and back bonding, anion-anion bonding and anionic clusters all find fruitful extension and elaboration in solid state chemistry. What is important is that there should be a continuous dialogue between the practitioners of both the disciplines, that would be mutually beneficial and rewarding to both the communities, enriching the science in the process.

\section{Acknowledgements}

J G thanks all his co-workers (whose names appear under the list of references) for their contribution to help him in the pursuit of solid state chemistry. He also thanks the Department of Science and Technology (DST), Government of India, for the award of a Ramanna Fellowship and the Indian National Science Academy (INSA) for the award of a Senior Scientist Position. Our thanks are due to the DST and the Council of Scientific and Industrial Research (CSIR) for grant of research projects to $J$ and a fellowship to R M. Special thanks of J G are due to Professor C N R Rao for his continued support and encouragement in the pursuit of a career in solid state chemistry.

\section{References}

1. Jäschke T and Jansen M 2006 J. Mater. Chem. 16 2792

2. Sleight A W 1998 Inorg. Chem. 372854

3. Grätzel M 2001 Nature $\mathbf{4 1 4} 338$

4. Tachikawa T, Fujitsuka M and Majima T $2007 \mathrm{~J}$. Phys. Chem. C111 5259

5. Steele B C H and Heinzel A 2001 Nature 414345

6. Tarascon J-M and Armand M 2001 Nature 414 359

7. Kauzlarich S M, Brown S R and Snyder G J 2007 Dalton Trans. 2099 
8. Schlapbach L and Züttel A 2001 Nature 414353

9. Theme issue: new energy materials $2007 \mathrm{~J}$. Mater. Chem. 173053 (Guest Editor: M Saiful Islam)

10. Eisenberg R and Nocera D G 2005 Inorg. Chem. 44 6799

11. Felser C, Fecher G H and Balke B 2007 Angew. Chem. Intl. Ed. 46668

12. Eerenstein W, Mathur N D and Scott J F 2006 Nature 442759

13. Kabbour H, Cario L, Jobic S and Corraze B $2006 \mathrm{~J}$. Mater. Chem. 164165

14. Cross L E 2004 Nature 43224

15. Sleight A W 1995 Acc. Chem. Res. 28103

16. Ball P 2006 Nature $\mathbf{4 4 2} 500$

17. (a) See for example, Shriver D F and Atkins P W 2002 Inorganic chemistry 3rd edn (OUP); (b) Smith D W 1987 J. Chem. Edu. 64480

18. Rao C N R and Gopalakrishnan J 1997 New directions in solid state chemistry 2nd edn (CUP)

19. Bhuvanesh N S P 1997 Ph D thesis, Indian Institute of Science, Bangalore

20. Shukoor M I, Therese H A, Gorgishvili L, Glasser G, Kolb U and Tremel W 2006 Chem. Mater. 182144

21. Ganapathi L, Ramanan A, Gopalakrishnan J and Rao C N R 1986 J. Chem. Soc., Chem. Commun. 62

22. Gopalakrishnan J, Bhuvanesh N S P and Raju A R 1994 Chem. Mater. 6373

23. Nedjar R, Borel M M and Raveau B 1985 Mater. Res. Bull. 201291

24. Livage J 1991 Chem. Mater. 3578

25. Bhat V and Gopalakrishnan J 1988 Solid State Ionics 2625

26. Bhuvanesh N S P and Gopalakrishnan J 1995 Inorg. Chem. 343760

27. Gopalakrishnan J 1995 Chem. Mater. 71265

28. Gopalakrishnan J and Bhat V 1987 Inorg. Chem. 26 4299

29. Bhuvanesh N S P, Prasad B R, Subramanian C K and Gopalakrishnan J 1996 Chem. Commun. 289

30. Goodenough J B 1974 in Solid state chemistry (ed) C N R Rao (New York: Marcel Dekker)

31. Rouxel J 1997 Curr. Sci. 7331

32. Bhat V and Gopalakrishnan J 1986 J. Chem. Soc., Chem. Commun. 1644

33. Ramesha K and Gopalakrishnan J 1999 J. Chem. Soc., Chem. Commun. 1173

34. Gopalakrishnan J and Rangan K K 1992 Chem. Mater. 4745

35. Rangan K K, Prasad B R, Subramanian C K and Gopalakrishnan J 1994 J. Chem. Soc., Chem. Commun. 141

36. Ramesha K and Gopalakrishnan J 2001 Solid State Sciences 3113

37. Crosnier M P, Guyomard D, Verbaere A, Piffard Y and Tournoux M 1992 J. Solid State Chem. 98128

38. Sivakumar T and Gopalakrishnan J 2002 Chem. Mater. 143984

39. (a) Gopalakrishnan J, Chattopadhyay A, Ogale S B, Venkatesan T, Greene R L, Millis A J, Ramesha K, Hannoyer B and Marest G 2000 Phys. Rev. B62 9538; (b) Sleight A W and Weiher J F 1972 J. Phys.
Chem. Solids 33 679; (c) Nag A, Manjanna J, Tiwari R M and Gopalakrishnan J 2008 Chem. Mater. 20 4420

40. Ramesha K, Thangadurai V, Sutar D, Subramanyam S V, Subbanna G N and Gopalakrishnan J 2000 Mater. Res. Bull. 35559

41. Bassett J, Denney R C, Jeffery G H and Mendham J 1978 Vogel's textbook of quantitative inorganic analysis 4th edn (London: Longman)

42. Harris D C 1992 in Chemistry of superconductor materials (ed.) T Vanderah (Park Ridge: Noyes Publications)

43. Gopalakrishnan J, Vijayaraghavan R, Nagarajan R and Shivakumara C $1991 \mathrm{~J}$. Solid State Chem. 93 272; J. Solid State Chem. 96468

44. Gopalakrishnan J, Pandey S and Rangan K K 1997 Chem. Mater. 92113

45. Machida M, Kawamura K and Ito K 2004 Chem. Commun. 662

46. See, for example, Goodenough J B 2005 Solid State Sciences 7642

47. Vidyasagar K, Reller A, Gopalakrishnan J and Rao C N R 1985 J. Chem. Soc., Chem. Commun. 7

48. (a) Hiroi Z and Takano M 1995 Nature (London) 377 41; (b) Khasanova N R, Izumi F, Hiroi Z, Takano M, Huang Q and Santoro A 1996 Acta Crystallogr. C52 2381

49. (a) Poeppelmeier K R, Leonowicz M E and Longo J M 1982 J. Solid State Chem. 44 89; (b) Poeppelmeier K R, Leonowicz M E, Scanlon J C, Longo J M and Yelon W B 1982 J. Solid State Chem. 4571

50. (a) Goodenough J B 2004 Rep. Prog. Phys. 67 1915; (b) Maris G, Ren Y, Volotchaev V, Zobel C, Lorenz T and Palstra T T M 2003 Phys. Rev. B67 224423

51. Maignan A, Martin C, Pelloquin D, Nguyen N and Raveau B 1999 J. Solid State Chem. 142247

52. Cava R J 2004 J. Chem. Soc., Dalton Trans. 2979

53. Itoh M, Shikano M and Shimura T 1995 Phys. Rev. B51 16432

54. Granado E, Huang Q, Lynn J W, Gopalakrishnan J and Ramesha K 2004 Phys. Rev. B70 214416

55. Cotton F A and Wilkinson G 1976 Advanced inorganic chemistry 3rd edn (New Delhi: Wiley Eastern)

56. Lufaso M W and Woodward P M 2004 Acta Crystallogr. B60 10

57. (a) Bhuvanesh N S P and Gopalakrishnan J $1997 \mathrm{~J}$. Mater. Chem. 72297 and the references given therein; (b) Halasyamani P S and Poeppelmeier K R 1998 Chem. Mater. 102753

58. Stoll S L, Stacy A M and Torardi C C 1994 Inorg. Chem. 332761

59. Byeon S-H, Park K and Itoh M 1996 J. Solid State Chem. 121430

60. Sivakumar T, Ramesha K, Lofland S E, Ramanujachary K V, Subbanna G N and Gopalakrishnan J 2004 Inorg. Chem. 431857

61. Sivakumar T, Lofland S E, Ramanujachary K V, Ramesha K, Subbanna G N and Gopalakrishnan J 2004 J. Solid State Chem. 1772635

62. Keller H, Bussmann-Holder A and Alex Müller K 2008 Mater. Today 1138 
63. (a) Day P 1981 Int. Rev. Phys. Chem. 1 149; (b) Day P, Hush N S and Clark R J H 2008 Philos. Trans. R. Soc. London, Ser. A 366, 5

64. Cox D E and Sleight A W 1979 Acta Crystallogr. B35 1

65. Brunschwig B S, Creutz C and Sutin N 2002 Chem. Soc. Rev. 31168

66. See for example Creutz C, Ford P C and Meyer T J 2006 Inorg. Chem. 45 7059; Henry Taube: Inorganic chemist extraordinaire

67. Larsson S 2008 Philos. Trans. R. Soc. London, Ser. A 366,47

68. Shenoy V B and Rao C N R 2008 Philos. Trans. R. Soc. London, Ser. A 366, 63

69. Attfield J P, Bell A M T, Rodriguez-Martinez L M, Greneche J M, Cernik R J, Clarke J F and Perkins D A 1998 Nature (London) 396655 and the references given therein

70. (a) Sleight A W 1988 Proc. Robert A. Welch Found. Conf. Chem. Res. XXXII 123; (b) Sleight A W 1988 Science 2421519

71. Cava R J 2000 J. Am. Ceram. Soc. 835

72. (a) Simon A 1997 Angew. Chem. Intl. Ed. 36 1788; (b) Deng S, Simon A and Köhler J 2005 Structure and Bonding 114103

73. (a) Reznik D, Pintschovius L, Ito M, Iikubo S, Sato M, Goka H, Fujita M, Yamada K, Gu G D and Tranquada J M 2006 Nature (London) 440 1170; (b) Zaanen J 2006 Nature (London) 4401118

74. Khasanov R, Shengelaya A, Maisuradze A, La Mattina F, Bussmann-Holder A, Keller H and Müller K A 2007 Phys. Rev. Lett. 98057007

75. Deng S, Simon A and Köhler J 1998 Angew. Chem. Intl. Ed. 37640

76. Liu X, Moritomo Y, Nakamura A and Kojima N 1999 J. Phys. Soc. Japan 683134

77. (a) Alonso J A, Martinez-Lope M J, Casais M T, Aranda M A G and Fernandez-Diaz M T $1999 \mathrm{~J}$. Am. Chem. Soc. 121 4754; (b) Alonso J A, Martinez-Lope
M J, Casais M T, Garcia-Munoz J L and FernandezDiaz M T 2000 Phys. Rev. B61 1756

78. Sleight A W, Gillson J L and Bierstedt P E 1975 Solid State Commun. 1727

79. (a) Krebs H 1975 Prog. Solid State Chem. 9 269; (b) Takahashi H, Igawa K, Arii K, Kamihara Y, Hirano M and Hosono H 2008 Nature 453 376; (c) Rotter M, Tegel M and Johrendt D 2008 Phys. Rev. Lett. 101 107006; (d) Zaanen J 2009 Nature 457546

80. Corbett J D 2000 Inorg. Chem. 395178

81. Simon A 1981 Angew. Chem. Intl. Ed. 201

82. Yvon K 1979 Current Topics in Materials Science $\mathbf{3}$ 53 (ed.) E Kaldis (Amsterdam: North-Holland)

83. Rao C N R and Gopalakrishnan J 1987 Acc. Chem. Res. 20228

84. Nanjundaswamy K S, Vasanthacharya N Y, Gopalakrishnan J and Rao C N R 1987 Inorg. Chem. 264286

85. Nanjundaswamy K S and Gopalakrishnan J 1987 J. Solid State Chem. $\mathbf{6 8} 188$

86. Torardi C C and McCarley R E $1979 \mathrm{~J}$. Am. Chem. Soc 1013963

87. Goodenough J B 1971 Prog. Solid State Chem. 5145

88. Rogers D B, Shannon R D, Sleight A W and Gillson J L 1969 Inorg. Chem. 8841

89. Jacob K T, Saji V S, Gopalakrishnan J and Waseda Y 2007 J. Chem. Thermodynamics 391539

90. (a) Donohue P C, Katz L and Ward R 1965 Inorg. Chem. 4 306; (b) Hong S-T and Sleight A W $1997 \mathrm{~J}$. Solid State Chem. 128251

91. Rijssenbeek J T, Jin R, Zadorozhny Yu, Liu Y, Bat$\operatorname{logg}$ B and Cava R J 1999 Phys. Rev. B59 4561

92. Gönen Z S, Gopalakrishnan J, Eichhorn B W and Greene R L 2001 Inorg. Chem. 404996

93. Khalifah P, Nelson K D, Jin R, Mao Z Q, Liu Y, Huang Q, Gao X P A, Ramirez A P and Cava R J 2001 Nature (London) 411669

94. Mani R, Fischer M, Joy J E, Gopalakrishnan J and Jansen M 2009 Solid State Sciences 11189 